THE EFFECTS OF A PERTURBED SOURCE ON CONTA MINANT TRANSPORT NEAR

THE WELDON SPRING QUARRY

ANL $/$ EES-TM--3

DE89 010543

by

D. Tomasko

Energy and Environmental Systems Division

March 1989

work sponsored by

U.S. DEPARTMENT OF LNERGY Oak Ridge Operations Office 


\section{CONTENTS}

FOREWORD

ABSTRACT

1 BACKGROUND

1.1 Objective

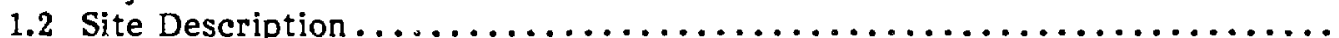

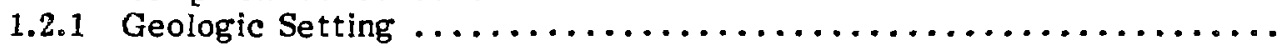

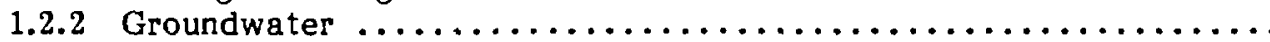

2 CONTAMINANT TRANSPORT MODEL $\ldots \ldots \ldots \ldots \ldots \ldots \ldots \ldots \ldots \ldots \ldots \ldots \ldots \ldots \ldots$

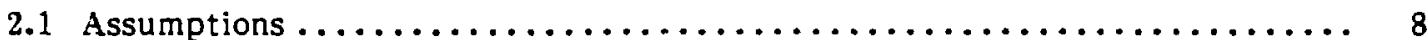

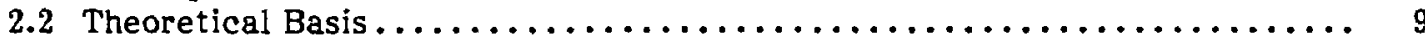

3 PARAMETER VALUES AND RANGES $\ldots \ldots \ldots \ldots \ldots \ldots \ldots \ldots \ldots \ldots \ldots \ldots \ldots \ldots$

4 RESULTS AND DISCUSSION $\ldots \ldots \ldots \ldots \ldots \ldots \ldots \ldots \ldots \ldots \ldots \ldots \ldots \ldots \ldots \ldots$

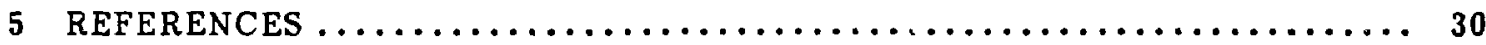

\section{FIGURES}

1 Location of the Weldon Spring Site, Weldon Spring, Missouri...$\ldots \ldots \ldots \ldots$

2 Location of the Weldon Spring Quarry Relative to the Missouri River and the Municipal Well Field....

3 Idealized Vertical Section through the Weldon Spring Quarry

4 Detailed North-South Vertical Section through the Weldon Spring

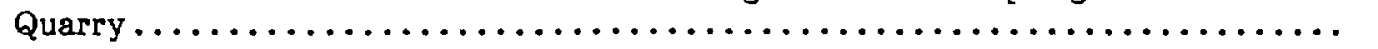

5 Water Levels Measured near the Weldon Spring Quarry in $1987 \ldots \ldots \ldots \ldots \ldots$

6 Simple Step Function Source for the Weldon Spring Quarry Model $\ldots \ldots \ldots \ldots \ldots$

7 Multiple-Stepped Function Source for the Weldon Spring Quarry Model $\ldots \ldots \ldots$. 13

8 Solute Concentration as Function of Time for Various Separation

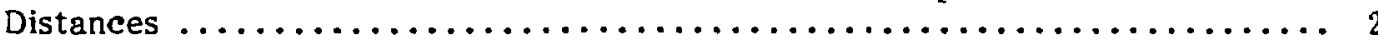

9 Maximum Change in $\mathrm{C} / \mathrm{C}_{0}$ as a Function of Distance from the Quarry $\ldots \ldots \ldots 21$

10 Solute Concentration as a Function of Time for Various Groundwater Velocities 


\section{FIGURES (Cont'd)}

11 Maximum Change in $\mathrm{C} / \mathrm{C}_{0}$ as a Function of the Average Linear

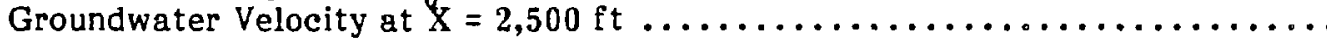

12 Solute Concentration as a Function of Time for Different Dispersion Coefficients

13 Solute Concentration as a Function of Time for Various Perturbation Amplitudes

14 Maximum Change in $\mathrm{C} / \mathrm{C}_{0}$ as a Function of the Amplitude of the

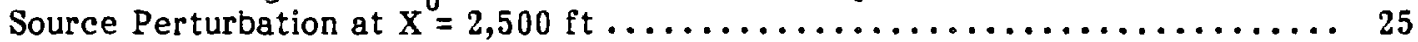

15 Solute Concentration as a Function of Time for Various Cleanup

16 Maximum Change in $\mathrm{C} / \mathrm{C}_{0}$ as a Function of the Duration of the Source Perturbation at $\mathrm{X}=2,500 \mathrm{ft}$

17 Solute Concentration as a Function of Time for Various Retardation Factors

18 Solute Concentration as a Function of Time for 500 yr at Maximum Retardation 


\section{FORRWORD}

The Weldon Spring site is located near Weldon Spring, Missouri, about $30 \mathrm{mi}$ west of St. Louis. At various times since the $1940 \mathrm{~s}$, portions of the site have been used as ordnance works by the U.S. Army and for uranium processing and waste storage facilities by the U.S. Atomic Energy Commission. As a restilt of these uses, two areas at the site -- the chemical plant and raffinate pits area and the quarry -- are contaminated with chemical and radioactive waste. On July 30, 1987, the U.S. Environmental Protection Agency (EPA) listed the quarry on its National Priorities List.

As current owner of the site, the U.S. Department of Energy is conducting the Weldon Spring Site Remedial Action Project as Major Project Number 182 under the Surplus Facilities Management Program (SFMP). The major goals of the SFMP are to eliminate potential hazards to the public and the environment that are associated with contamination at SFMP sites and to make surplus property available for other uses to the extent possible. Remedial actions under the SFMP are conducted in accordance with the National Environmental Policy Act and subject to EPA oversight under the Comprehensive Environmental Response, Compensation, and Liability Act, as amended by the Superfund Amendments and Reauthorization Act.

This report presents the results of solute transport modeling, which facilitates an analysis of the effects of disturbing the contaminant source (i.e., through remedial action) on nearby wells and surface water. The analysis is intended as an aid in selecting a remedial action alternative. 


\title{
THE EFFECTS OF A PERTURBED SOURCE ON \\ CONTAMINANT TRANSPORT NEAR \\ THE WELDON SPRING QUARRY
}

by

D. Tomasko

\begin{abstract}
The effects of a perturbed contamination source at the Weldon Spring quarry in St. Charles County, Missouri, on downstream solute concentrations were investigated using one-dimensional analytic solutions to an advection-dispersion equation developed for both constant-strength and multiple-stepped source functions. A sensitivity study using parameter base-case values and ranges consistent with the geologic conceptualization of the quarry area indicates that the parameters having the greatest effect on predicted concentrations are the distance from the quarry to the point of interest, the average linear groundwater velocity, the contaminant retardation coefficient, and the amplitude and duration of the source perturbation caused by response action activities. Use of base-case parameter values and realistic values for the amplitude and duration of the source perturbation produced a small effect on solute concentrations near the western extremity of the nearby municipal well field, as well as small uncertainties in the predicted results for the assumed model. The effect of simplifying assumptions made in deriving the analytic solution is unknown: use of a multidimensional flow and transport model and additional field work are needed to validate the model.
\end{abstract}

\section{BACEGROUND}

\subsection{OBJECTIVE}

The U.S. Department of Energy (DOE) plans to perform a response action at the Weldon Spring quarry. Specific activities that are a part of this action can be divided into five areas: (1) removal and treatment of contaminated water from the quarry pond and other sources, (2) removal of bulk wastes, (3) potential removal of any residual materials remaining after bulk-waste removal, (4) potential restoration of groundwater, and (5) potential restoration of nearby properties. This report presents analyses having three major objectives: (1) to estimate the effects of a perturbed contaminant source at the quarry on downstream solute concentrations, (2) to compare downstream concentrations for a no-action alternative with those calculated for the remedial action program, and (3) to perform a sensitivity study to assess the reliability of the predicted results. 


\subsection{SITE DESCRIPTION}

The Weldon Spring quarry is part of a DOE surplus facility located in St. Charles County, Missouri, about $4 \mathrm{mi}$ south of the Weldon Spring Chemical Plant and $30 \mathrm{mi}$ west of St. Louis (Fig. 1). The quarry is located near Route 94 about $700 \mathrm{ft}$ from the Femme Osage Slough, 3,000 ft from a municipal well field, and $1 \mathrm{mi}$ from the Missouri River (Fig. 2). Originally, the quarry was used to supply limestone and sand for construction. The 9-acre site was later used for the disposal of soils and other materials contaminated by trinitrotoluene (TNT) during the $1940 \mathrm{~s}$ and $1950 \mathrm{~s}$ and the disposal of low-level radioactive wastes during the late $1950 \mathrm{~s}$ and $1960 \mathrm{~s}$. The quarry is filled with alout $95,000 \mathrm{yd}^{3}$ of radioactively or chemically contaminated wastes, including drums, concrete and steel rubble, machinery, process residues, uncontained wastes, and contaminated soils.

\subsubsection{Geologic Setting}

The Weldon Spring quarry is located in low limestone hills near the west bank of the Missouri River. The mid-Ordovician bedrock of the quarry area is predominantly limestone and dolomite. Nearby are elevated deposits of Bushberg sandstone and silty clay. In the vicinity of the quarry, the carbonate rocks dip to the northeast at a gradient of 60-80 ft/mi (Berkeley Geosciences Associates 1984).

The bedrock is overlain in the upland areas by $10-40 \mathrm{ft}$ of silty clay derived primarily from glacial loess and till. In the Missouri River bottomland areas, the bedrock is overlain by up to $100 \mathrm{ft}$ of alluvial material. Figure 3 shows an idealized geologic section of the quarry. The sides of the quarry expose the Ordovician Kimmswick formation (Fig. 3), while the bedrock floor of the quarry, presently covered with clay and waste rubble, lies in the upper portion of the Decorah formation (Fig. 4). The Decorah formation is $20-40 \mathrm{ft}$ thick, and its upper portion is predominantly fossiliferous limestone with shale partings (Berkeley Geosciences Associates 1984). The Kimmswick formation, mined during quarry operations, is predominantly a crystalline limestone about $70 \mathrm{ft}$ thick. It is characterized by solution-enlarged features associated with the intersection of vertical joints and bedding planes.

East and south of the guarry (Fig. 3), bottomland alluvium, sand, and gravels replace the Plattin, Decorah, and Kimmswick limestones and shales. Locally, the alluvium is composed of a surficial layer of $10 \mathrm{ft}$ of silt underlain by about $20 \mathrm{ft}$ of sand. The thickness of the silt layer increases toward the river. Beneath the sand is about $70 \mathrm{ft}$ of sand and graveJ. This water-bearing alluvium is a major contributor to the domestic water supplies of nearby towns.

\subsubsection{Groundwater}

Groundwatel flow in the vicinity of the quarry occurs in alluvium, fractured limestone and dolomite, and the sandstone of the St. Peter formation (Berkeley Geosciences Associates 1984). Water-table conditions (unconfined aquifers) are typically found in areas of significant alluvial deposits; semiconfined conditions (confined to leaky aquifers) occur where layers of varying permeability are present. Flow in the limestone 


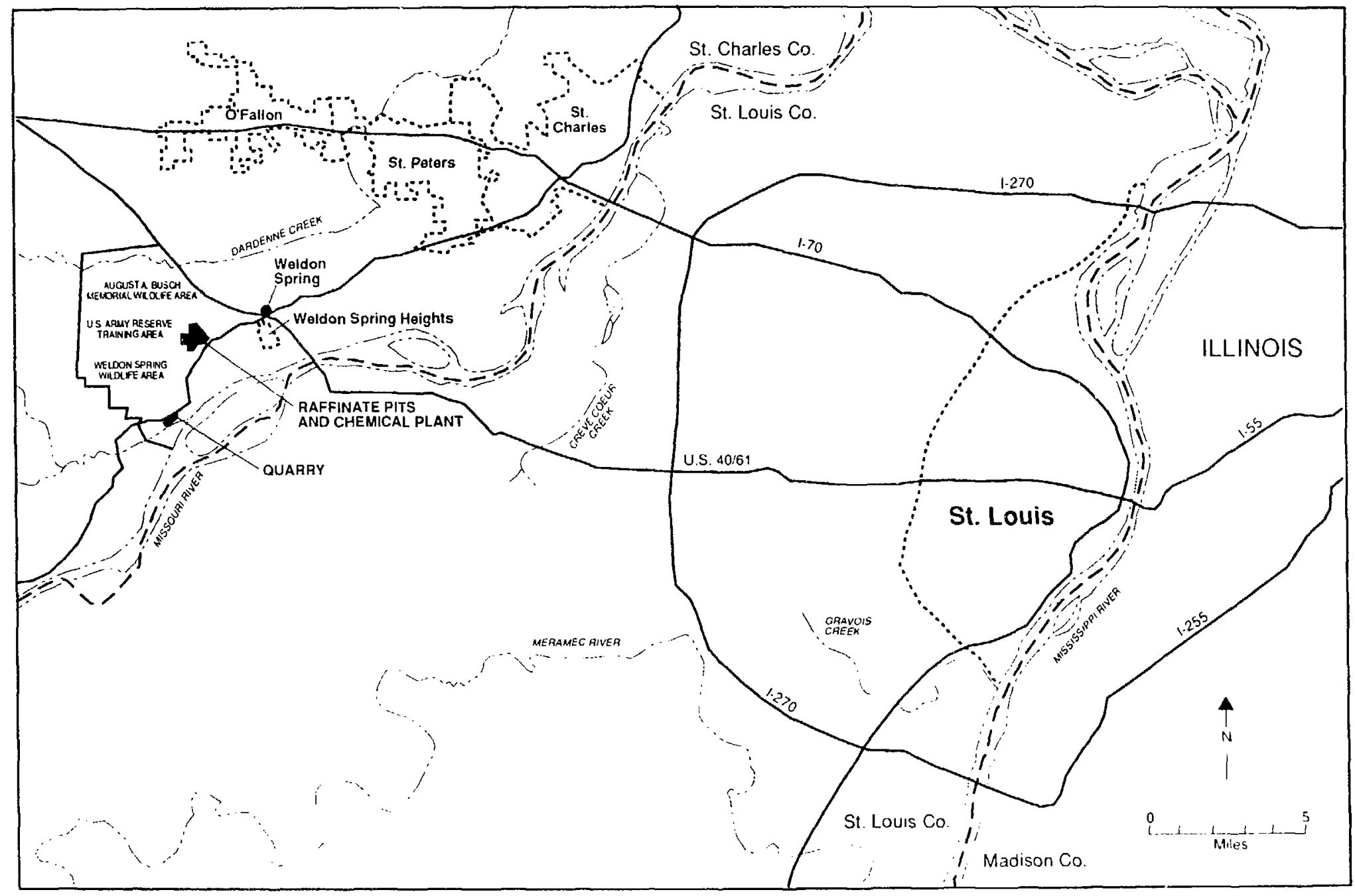

FIGURE 1 Location of the Weldon Spring Site, Weldon Spring, Missouri (Source: MacDonnell et al. 1989) 


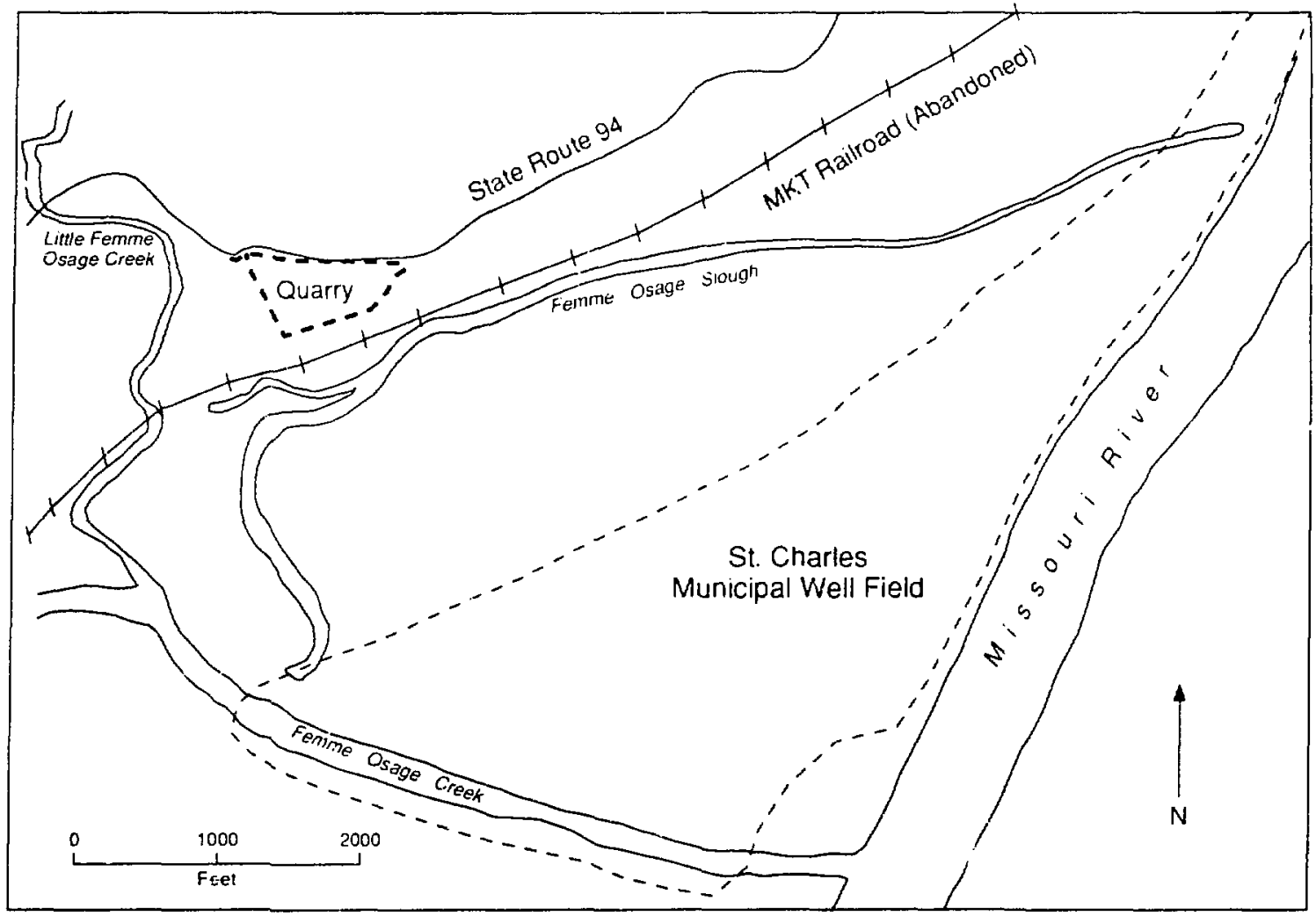

FIGURE 2 Location of the Weldon Spring Quarty Relative to the Missouri River and the Municipal Well Field

is primarily through secondary porosity provided by fractures and solution fegtures. The St. Peter formation, about $300 \mathrm{ft}$ below the floor of the quarry, contains a confined groundwater aquifer. The degree of connection between the St. Peter formation and overlying formations is not fully understood.

A shallow groundwater divide is believed to exist beneath a ridge that runs through the Weldon Spring Chemical Plant, about $4 \mathrm{mi}$ north of the quarry. As a result of this divide, shallow groundwater flow near the quarry is expected to be in a southeasterly direction toward the Missouri River. Water levels measured on September 5, 1980, support this hypothesis.

In the immediate vicinity of the quarry, groundwater flows primarily from north to south (Morrison-Knudson Engineers, Inc. 1988), although water-level measurements taken in 1987 indicate a possible mounding of groundwater at the quarry, due to local recharge (Fig. 5). If groundwater flow in the fractured bedrock below the quarry is assumed to be primarily horizontal (low vertical leakage), then groundwater flow near the quarry can be modeled as if it were one-dimensional. This approach should produce conservative estimates for the downstream solute concentrations. 


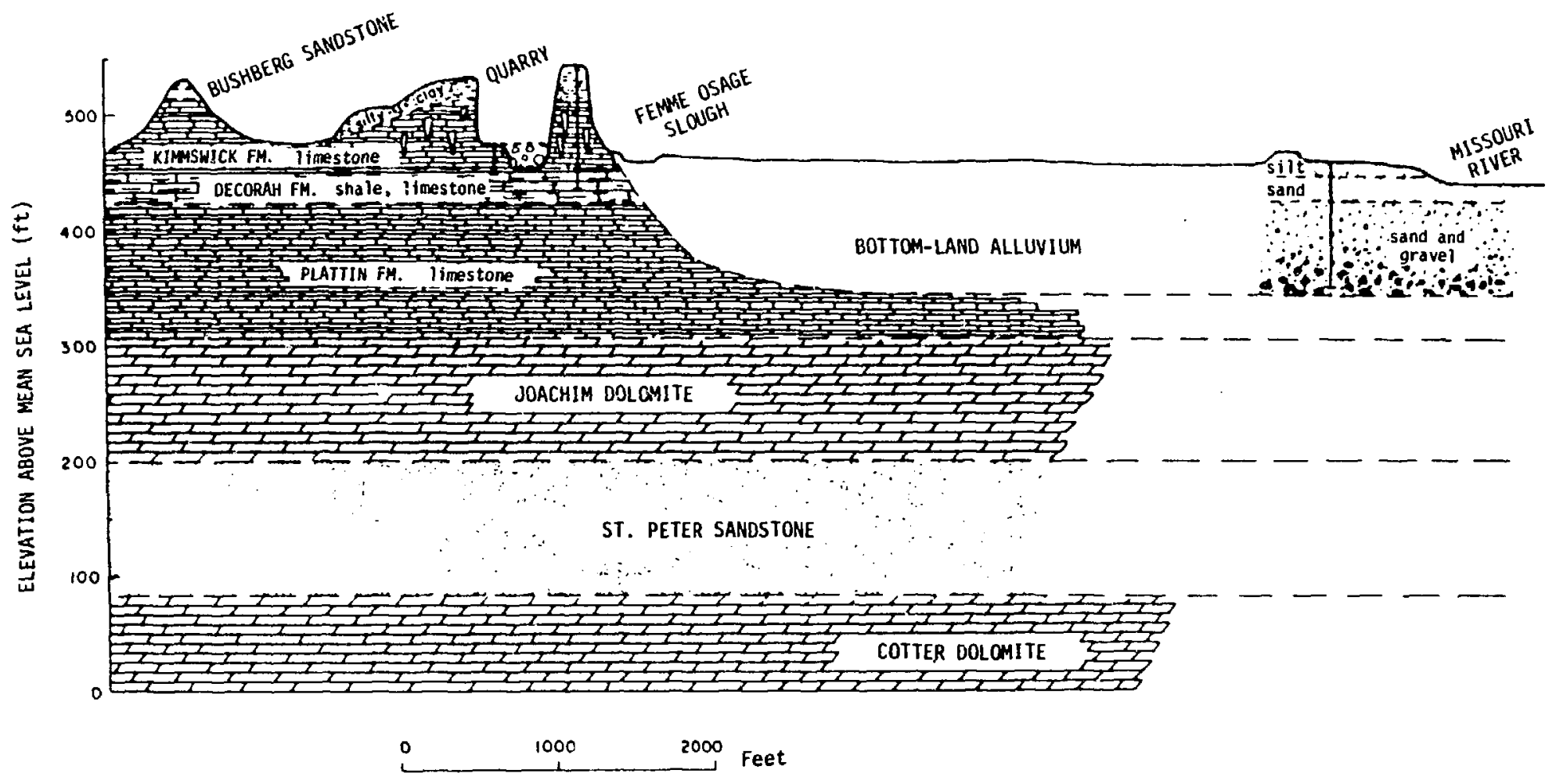

FIGURE 3 Idealized Vertical Section through the Weldon Spring Quarry (Source: Berkeley Geosciences Associates 1984) 


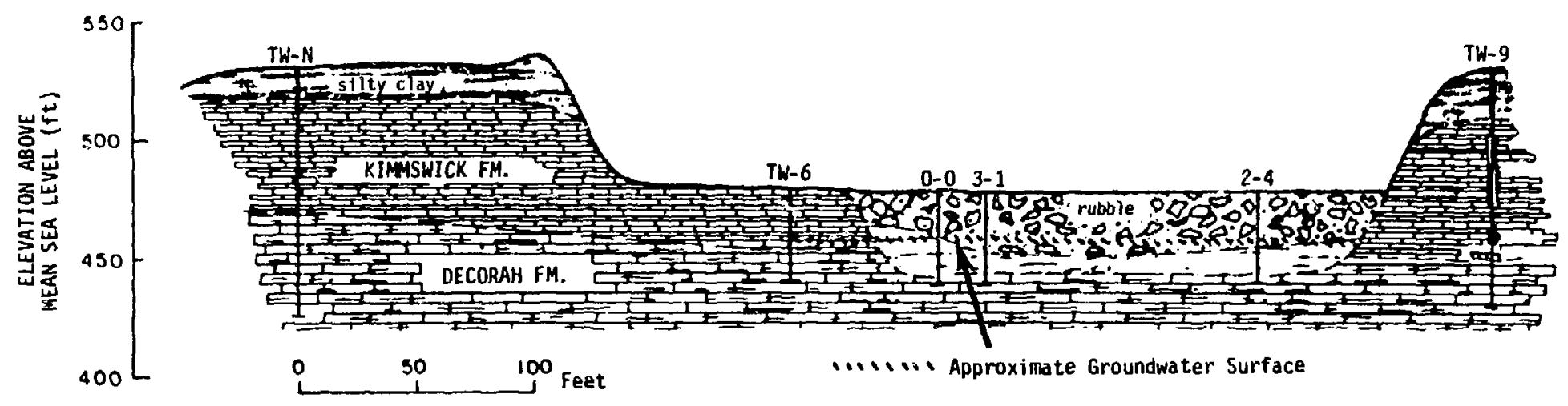

FIGURE 4 Detailed North-Snuth Vertical Section through the Weldon Spring Quarry (Source: Berkeley Geosciences Associates 1984) 


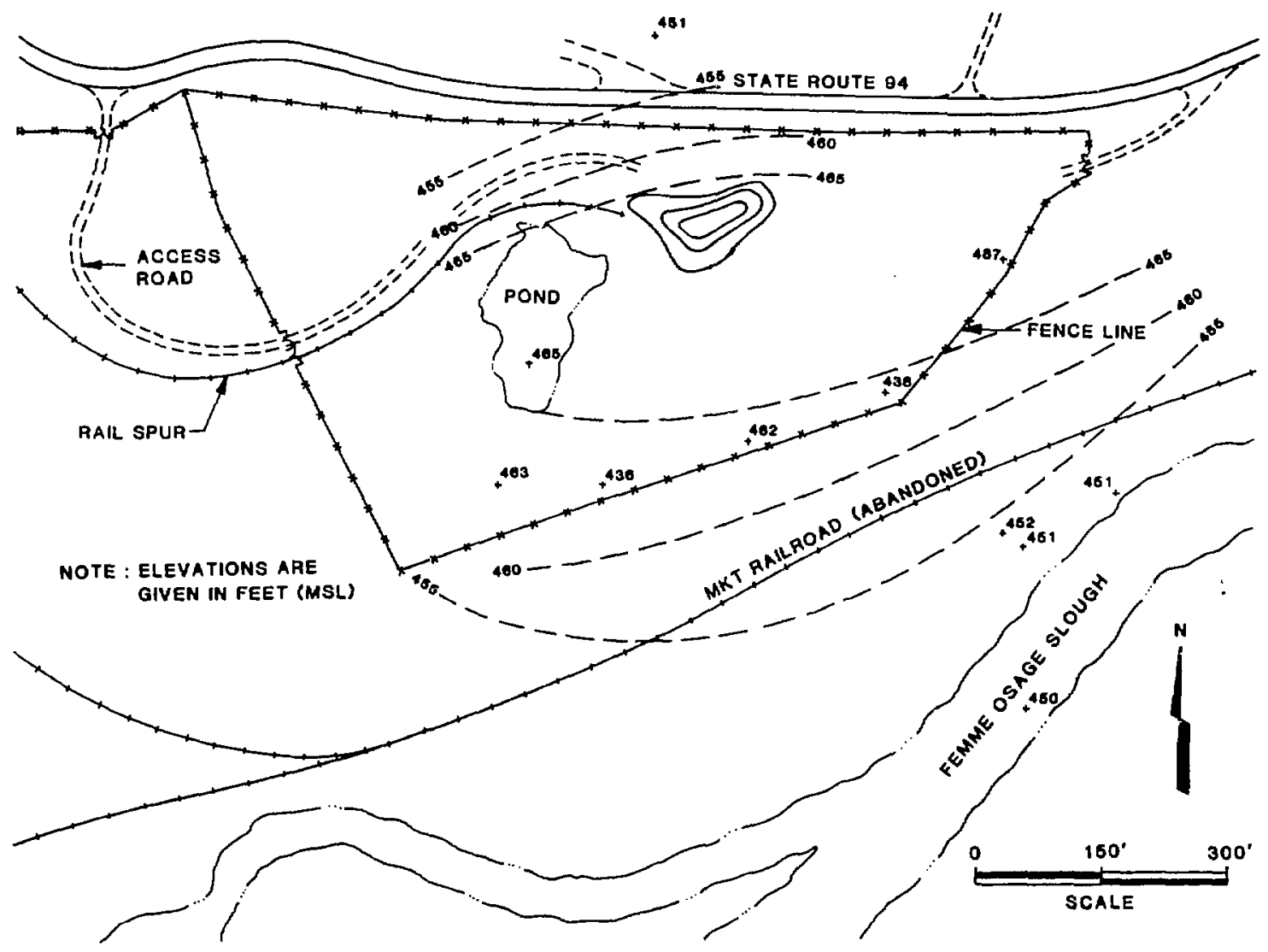

FIGURE 5 Water Levels Measured near the Weldon Spring Quarry in 1987 (Source: Adapted from MacDonnell et al. 1989)

Contaminated water from the quarry is thus expected to flow toward the Femme Osage Slough and the St. Charles municipal well field, which is completed in the alluvium and located near the Missouri River (Fig. 2). Near the quarry, flow is likely to take place through secondary porosity features in the fractured limestone formations. Near the well field, the flow may be a combination of flow through fractures and flow through a porous medium composed of bottomland alluvium. 


\section{CONTAMINANT TRANSPCRT MODEL}

\subsection{ASSUMPTIONS}

This section presents the development of an analytical model for predicting the effects of a perturbed source on contaminant transport. In order to develop a closedform, analytical solution, simplifying assumptions were made for both the groundwater flow system and the processes affecting contaminant transport. These simplifications are discussed below.

The first approximation made in developing an analytical expression for contaminant transport from a perturbed source was that the groundwater flow system is one-dimensional in a direction approximately parallel to the observed hydraulic gradient. On a regional scale, groundwater flow passes through the quarry area in a northwest to southeast direction, as indicated by the water levels shown in Fig. 5. In the immediate vicinity of the quarry, the ponded water may act as a local hydrologic high. Water levels shown in Fig. 5 indicate that the predominant groundwater flow direction is also to the south and east. For a narrow contaminant plume, groundwater flow in a plane parallel to the surface can be considered one-dimensional. Although flow in the vertical direction (formation to formation) is possible, no data are currently available to assess the vertical leakage rate. For simplicity, it was assumed to be zero.

In addition to the assumption of one-dimensional flow, the rock matrix was assumed to be homogeneous and isotropic from the quarry to the Missouri River. Variations in material properties between river alluvium and fractured limestone were accounted for by assuming a range of constant flow velocities for the transport calculations. Choosing an appropriate range of velocities allows a conservative calculation to be performed.

For both the river alluvium and fractured dolomite and limestone, an equivalent single-porosity medium was used for the calculations. As demonstrated by Tomasko et al. (1987), a fractured porous medium can behave in one of three ways: (1) as an equivalent single-porosity medium with a total porosity equal to the sum of the fracture and matrix porosities, (2) as an equivalent single-porosity medium with a total porosity equal to that of the fracture alone (fracture flow), or (3) as a double-porosity system (Streltsova-Adams 1978) in which the fractures provide a high-permeability channel of low storativity and the surrounding rock matrix provides a low-permeability medium with high storativity. For the fractured quarry limestone, the equivalent porous medium appears to behave like a type 2 system (Berkeley Geosciences Associates 1984). Flow appears to be confined to the fractures, and the surrounding intact limestone provides little permeability for flow or storage. For the river alluvium, the system should behave like an ideal porous medium.

The velocities used in the transport calculations were chosen to be representative of an equivalent porous medium that simulates an average flow through two systems: (1) a fractured limestone and (2) a flood plain alluvium. Since the flow velocities through the alluvium can be much lower than fracture flow velocities, the velocities used in this study are significantly lower than the velocity expected in any 
individual fracture. This approximation is consistent with recent concentration measurements made in the alluvium north and south of the Femme Osage Slough, which irdicate low average velocities and long travel times between the quarry and the points of measurement (Morrison-Knudson Engineers, Inc. 1988). No groundwater flow calculations were performed for this study.

In all of the calculations, the Femme Osage Slough and the municipal well field were assumed to have a negligible effect on the flow pattern in the vicinity of the quarry. The effects of this assumption on the calculated results are unknown at this time and will be investigated further with a more detailed multidimensional numerical model and validated with additional field measurements as part of a groundwater restoration decision process.

In addition to the above assumptions about the groundwater flow system, the following assumptions were made for performing the transport calculations: solutes from the quarry im mediately enter a zone of saturated groundwater (no vadose), the half-lives of any radionuclides in the groundwater are long compared to the time scale of the calculations, a point source of contamination has existed at the quarry for $40 \mathrm{yr}$, perturbations to the quarry source caused by response activities can be represented with a simple time-dependent multistep function, and sorption can be represented with a linear isotherm (reactions are fast and reversible). In general, these assumptions should produce conservative predictions for the downstream solute concentrations.

\subsection{THEORETICAL BASIS}

The following partial differential advection-dispersion equation from Freeze and Cherry (1979) describes the transport of a contaminant under steady-state flow conditions for the above simplifying assumptions:

$$
\frac{\partial C}{\partial t}+\frac{V}{R} \frac{\partial C}{\partial X}=\frac{D}{R} \frac{\partial^{2} C}{\partial X^{2}}
$$

where:

$\mathbf{R}=$ Solute retardation factor given by:

$$
R=1+\frac{\rho_{b}}{\phi} K_{d}
$$

$$
\begin{aligned}
{ }^{\circ}= & \text { Bulk density, } \\
C= & \text { Concentration of the contaminant, } \\
V= & \begin{array}{l}
\text { Average linear groundwater veloaity (Darcy velocity/effective } \\
\text { porosity) }
\end{array}
\end{aligned}
$$




$$
\begin{aligned}
D & =\text { Dispersion coef ficient, } \\
t & =\text { Time, } \\
K_{d} & =\text { Distribution coefficient, } \\
\phi & =\text { Effect ve porosity, and } \\
X & =\text { Distance from the quarry in a direction parallel to groundwater } \\
& \text { flow. }
\end{aligned}
$$

The dispersion coefficient, $D$, was assumed to follow the functional form presented by Bear (1972):

$$
\mathrm{D}=\mathrm{aV}
$$

where $\alpha=$ dispersivity. Diffusional effects were assumed to be negligible.

Dispersivity was generally assumed to depend on scale:

$$
\alpha=0.1 \mathrm{~L}
$$

where $L$ is the separation distance between the origin of the source $(X=0)$ and the point of measurement (Lallemand-Barres and Peaudecerf 1978). At large separations, dispersivity appears to approach a maximum value of about $500 \mathrm{ft}$ (Grisak and Pickens 1980). Therefore, a maximum value of $\alpha=500 \mathrm{ft}$ was assumed for the calculations in this study, giving

$$
\begin{aligned}
& a=0.1 \mathrm{~L} \text { for } 0.1 \mathrm{~L} \leq 500 \mathrm{ft} \\
& a=500 \mathrm{ft} \text { for } 0.1 \mathrm{~L}>500 \mathrm{ft} .
\end{aligned}
$$

For a constant source $C_{0}$ at $X=0$, Eq. 1 has the following solution in Laplace space:

$$
\frac{\bar{C}}{C_{0}}=\frac{1}{S} e^{V X / 2 D} e^{-\sqrt{V^{2} x^{2} / 4 D^{2}+S x^{2} R / D}}
$$

In Eq. $6, \mathbf{S}$ is the Laplace variable and $\bar{C}$ is the solute concentration in Laplace space. Equation 6 has the form:

$$
\frac{1}{S} e^{-\sqrt{A(B+S)}}
$$


The inverse Laplace trinsform of Eq. 7 is given in the tables of Ditkin and Prudnikov (1967) as:

$$
\begin{aligned}
L^{-1}\left[\frac{e^{-\sqrt{A(B+S)}}}{S}\right]= & \frac{1}{2}\left[e^{-\sqrt{A B}} \operatorname{ERFC}\left(\frac{1}{2} \sqrt{A / t}-\sqrt{B t}\right)\right. \\
& \left.+e^{\sqrt{A B}} \operatorname{ERFC}\left(\frac{1}{2} \sqrt{A / t}+\sqrt{B t}\right)\right]
\end{aligned}
$$

where ERFC is the complementary error function given by Hildebrand (1976) as:

$$
\operatorname{ERFC}(\gamma)=1-\operatorname{ERF}(\gamma)=1-2 / \sqrt{\pi} \int_{0}^{\gamma} e^{-\lambda^{2}} d \lambda
$$

The inverse Laplace transform of Eq. 6 can be found by using the inverse relationship presented in Eq. 8 . The result is:

$$
\begin{aligned}
\frac{C}{C_{0}} & =\frac{e^{V X / 2 D}}{2}\left[e^{-\sqrt{A B}} \operatorname{ERFC}\left(\frac{1}{2} \sqrt{A / t}-\sqrt{B E}\right)\right. \\
& \left.+e^{\sqrt{A B}} \operatorname{ERFC}\left(\frac{1}{2} \sqrt{A / t}+\sqrt{B t}\right)\right]
\end{aligned}
$$

where:

$$
A=\frac{R x^{2}}{D}
$$

and

$$
B=\frac{v^{2}}{4 D R}
$$

Reintroducing the physical parameters gives:

$$
\frac{C}{C_{0}}=\frac{1}{2}\left[\operatorname{ERFC}\left(\frac{X R-V t}{2 \sqrt{D R t}}\right)+e^{V X / D} \operatorname{ERFC}\left(\frac{X R+V t}{2 \sqrt{D R t}}\right)\right]
$$

For no sorption ( $\mathrm{R}=1$ ), Eq. 13 reduces to the well-known analytic solution first presented by Ogata and Banks (1961):

$$
\frac{C}{C_{0}}=\frac{1}{2}\left[\operatorname{ERFC}\left(\frac{x-V t}{2 \sqrt{D t}}\right)+e^{V X / D} \operatorname{ERFC}\left(\frac{x+V t}{2 \sqrt{D t}}\right)\right]
$$

Equations 13 and 14 were used to calculate the downstream solute concentration for the no-action alternative. 
For a simple step function, the concentration at $\mathrm{X}=0$ is no longer constant with time. Instead, at time $=0$ the concentration is $C_{0}$, ans remains $C_{0}$ until time $=\Delta t_{1}$, at which point the concentration returns to zero (Fig. 6). This type of process represents cleanup of the quarry without any increase in the contaminant source distribution. At $\mathrm{X}=0$, the time-dependent source concentration is given by the following expression:

$$
\frac{C}{C_{0}}=U(t-0)-U\left(t-\Delta t_{1}\right)
$$

where $U$ is the unit function (Hildebrand 1976).

The Laplace-transformed source distribution is given by:

$$
\frac{\bar{c}}{c_{0}}=\frac{1}{s}\left(1-e^{-\Delta t} t_{1}\right)
$$

The solution to Eq. 1 in Laplace space for a simple step function source at $\mathrm{X}=0$ is given by:

$$
\frac{\bar{C}}{C_{0}}=\frac{1}{S}\left(1-e^{-\Delta t} s\right) e^{V x / 2 D} e^{-\sqrt{v^{2} x^{2} / 4 D^{2}+S x^{2} R / D}}
$$

This expression can be inverted term-wise to yield the time-dependent solute concentration for one-dimensional transport with advection, dispersion, and retardation using Eq. 8 and the following shift identity for Laplace transforms (Hildebrand 1976):

$$
e^{-\Delta t S} f(S)=[[f(t-\Delta t) H(t-\Delta t)]
$$

where $\mathrm{H}$ is the Heaviside function (Hildebrand 1976) such that:

$$
\begin{aligned}
& H(t-\Delta t)=0 \text { for } t<\Delta t \\
& H(t-\Delta t)=1 \text { for } t \geq \Delta t
\end{aligned}
$$

The result is given by the following expression:

$$
\begin{aligned}
\frac{C}{C_{0}}= & \frac{1}{2}\left[\operatorname{ERFC}\left(\frac{X R-V T}{2 \sqrt{D R t}}\right)+e^{V X / D} \operatorname{ERFC}\left(\frac{X R+V t}{2 \sqrt{D R t}}\right)\right] \\
& -\frac{1}{2} H\left(t-\Delta t_{1}\right)\left\{\operatorname{ERFC}\left[\frac{X R-V\left(t-\Delta t_{1}\right)}{2 \sqrt{D R\left(t-\Delta t_{1}\right)}}\right]\right. \\
& \left.+e^{V X / D} \operatorname{ERFC}\left[\frac{X R+V\left(t-\Delta t_{1}\right)}{2 \sqrt{D R\left(t-\Delta t_{1}\right)}}\right]\right\}
\end{aligned}
$$




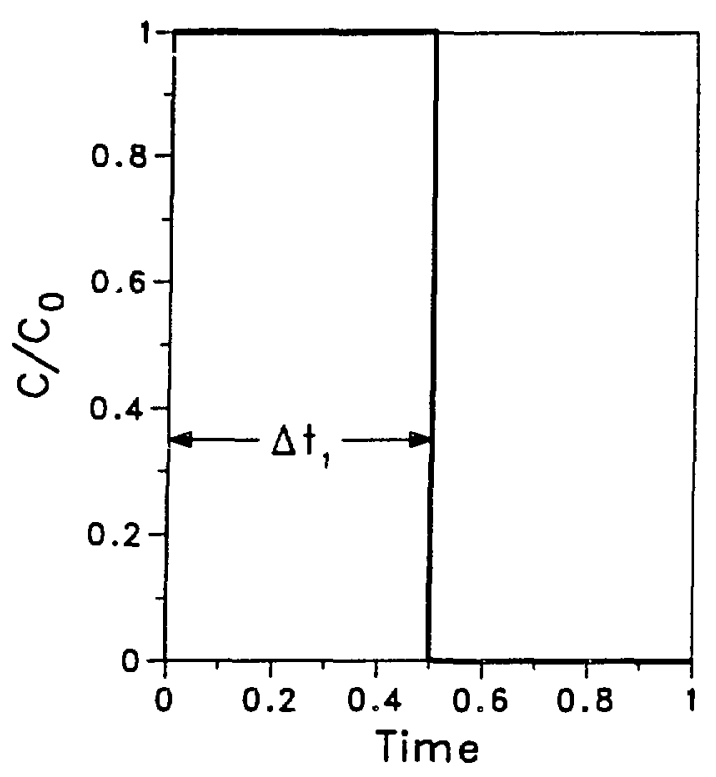

FIGURE 6 Simple Step Function Source for the Weldon Spring Quarry Model

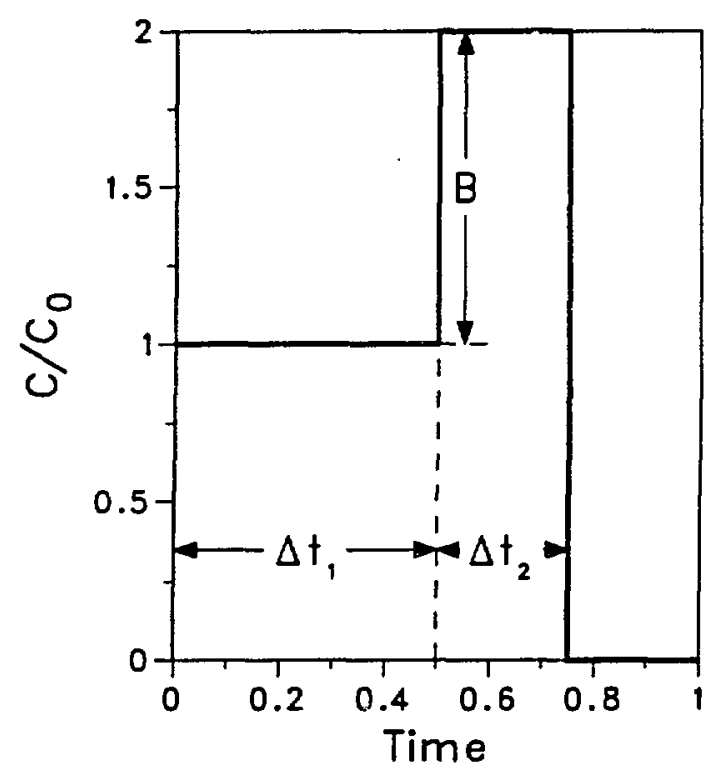

FIGURE 7 Multiple-Stepped Function Source for the Weldon Spring Quarry Model

For a multiple, stepped solute source (Fig. 7), the concentration at $\mathrm{X}=0$ can be represented with the following equation:

$$
\frac{C}{C_{0}}=U(t-0)+b U\left(t-\Delta t_{1}\right)-\left[(b+1) U\left(t-\Delta t_{1}-\Delta t_{2}\right)\right]
$$

where $b C_{0}$ is the amplitude of the source perturbation above $C_{0}, \Delta t_{1}$ is the duration of constant source strength $\mathrm{C}_{0}$, and $\Delta \mathrm{t}_{2}$ is the duration of the perturbed source strength. This source was used to simulate cleanup at the quarry with a perturbation in the source concentration.

In Laplace space, Eq. 21 becomes:

$$
\frac{\bar{c}}{c_{0}}=\frac{1}{s}\left[1+b e^{-\Delta t_{1} s}-(b+1) e^{-\left(\Delta t_{1}+\Delta t_{2}\right) s}\right]
$$

and the solution of Eq. 1 in Laplace space for a multiple, stepped-source function is:

$$
\begin{aligned}
\frac{\bar{C}}{C_{0}}= & \frac{1}{s}\left[1+b e^{-\Delta t_{1} S}-(b+1) e^{-\left(\Delta t_{1}+\Delta t_{2}\right) S}\right] \\
& \times\left(e^{V X / 2 D} e^{\left.-\sqrt{V^{2} x^{2} / 4 D^{2}+S x^{2} R / D}\right)}\right.
\end{aligned}
$$


The inverted analytic solution for one-dimensional solute transport with advection, dispersion, and retardation is then found term-wise, as before, using the Ditkin and Prudnikov (1967) relation and the Laplace transiorm shift identity. The result is:

$$
\begin{aligned}
\frac{c}{C_{0}}= & \frac{1}{2}\left[\operatorname{ERFC}\left(\frac{X R-V t}{2 \sqrt{D R t}}\right)+e^{V X / D} \operatorname{ERFC}\left(\frac{X R+V t}{2 \sqrt{D R t}}\right)\right] \\
& +\frac{b}{2} H\left(t-\Delta t_{1}\right)\left\{\operatorname{ERFC}\left[\frac{X R-V\left(t-\Delta t_{1}\right)}{2 \sqrt{D R\left(t-\Delta t_{1}\right)}}\right]\right. \\
& \left.+e^{V X / D} \operatorname{ERFC}\left[\frac{X R+V\left(t-\Delta t_{1}\right)}{2 \sqrt{D R\left(t-\Delta t_{1}\right)}}\right]\right\} \\
& -\frac{(b+1)}{2} H\left(t-\Delta t_{1}-\Delta t_{2}\right)\left\{\operatorname{ERFC}\left[\frac{X R-V\left(t-\Delta t_{1}-\Delta t_{2}\right)}{2 \sqrt{D R\left(t-\Delta t_{1}-\Delta t_{2}\right)}}\right]\right. \\
& \left.+e^{V X / D} \operatorname{ERFC}\left[\frac{X R+V\left(t-\Delta t_{1}-\Delta t_{2}\right)}{2 \sqrt{D R\left(t-\Delta t_{1}-\Delta t_{2}\right)}}\right]\right\}
\end{aligned}
$$

A computer program was written to evaluate Eqs. 13, 14, and 24 for a range of parameters relevant to conditions expected near the Weldon Spring quarry. The complementary error function, ERFC, was modeled using an algorithm from Abramowitz and Stegun (1972). To implement the algorithm, the following relationship was developed:

$$
\operatorname{ERFC}(-X)=2-\operatorname{ERFC}(X)
$$




\section{PARAMETER VALUES AND RANGES}

In calculating the downstream solute concentration with Eqs. 13 and 24, values were assigned to the following independent variables: the distance from the quarry to the point of interest, $X$, measured in a direction parallel to the direction of groundwater flow (northwest to southeast); the average linear velocity of the groundwater, $V$; the value of the dispersion coefficient, $D$; the amplitude of the perturbation, $b$; the duration of the constant source strength, $\Delta \mathrm{t}_{1}$; the duration of the source perturbation, $\Delta \mathrm{t}_{2}$; and the degree of solute retardstion, $R$. These values were then varied over ranges consistent with the geologic conceptualization of the quarry area to perform a sensitivity study to evaluate the reliability of the calculations. Details of the selection process for the parameter values and ranges are given below.

Three separation distances, $1,000,2,500$, and $5,000 \mathrm{ft}$, were used in the calculations performed for this study. These separation distances correspond to the approximate distances from the quarry to the Femme Osage Slough, the western extremity of the municipal well field, and the west bank of the Missouri River, respectively (Fig. 3). A base-case value of $2,500 \mathrm{ft}$ was used to investigate the effects of other parameters, except for retardation and dispersivity, on the downstream solute concentrations. This value was chosen because it provides a conservative estimate of the distance to the municipal well field $(2,700 \mathrm{ft})$. For retardation and dispersivity, a basecase value of $1,000 \mathrm{ft}$ was used to facilitate the graphical presentation. For all calculations, the porous medium between the quarry and the point of calculation was assumed to be homogeneous and isotropic.

In order to simulate different equivalent-porosity media, the average groundwater velocity was varied between 100 and $1,000 \mathrm{ft} / \mathrm{yr}$. A base-case value of $300 \mathrm{t} / \mathrm{yr}$ was selected to investigate the effects of other parameters on the downstream concentrations. The base-case velocity is consistent with point-dilution measurements made in the fractured limestone near the quarry (Berkeley Geosciences Associates 1934) and is a reasonable compromise between the high fluid velocities expected in the fractured limestcne and the low velocities expected in the flood plain alluvium.

Solute transport can be affected by dispersion as well as advection. As discussed earlier, dispersion was assumed to be the product of dispersivity and groundwater velocity (Eq. 3); diffusional effects here are assumed to be negligible. Dispersivity was assumed to depend on the scale, with a maximum value of $500 \mathrm{ft}$ (Eg. 5). The dispersion coefficient used in this study ranged from a low of $1.5 \times 10^{4} \mathrm{ft}^{2} / \mathrm{yr}$ to a high of $1.5 \times 10^{5} \mathrm{ft}^{2} / \mathrm{yr}$. For the sensitivity analysis, the dispersion coefficient was allowed to vary over three orders of magnitude $\left(3 \times 10^{3}\right.$ to $\left.3 \times 10^{6} \mathrm{ft}^{2} / \mathrm{yr}\right)$ for a separation distance of $1,000 \mathrm{ft}$ and a fluid velocity of $300 \mathrm{ft} / \mathrm{yr}$.

In addition to the above hydrogeologic parameters, downstream solute concentrations can be affected by $\Delta t_{1}, \Delta t_{2}$, and b. For all of the calculations, the duration time $\left(\Delta t_{1}\right)$ of the constant strength source $\left(C_{0}\right)$ was assumed to be 40 yr. This value corresponds to having a constant-value contaminant source in the quarry since the late 1940s. This assumption is valid for chemical contaminants such as residues from the manufacture of TNT, but it is about $10-15 \mathrm{yr}$ too long for radionuclide disposal in the 
early 1960s (Berkeley Geosciences Associates 1984). Since the predicted downstream solute concentrations achieve nearly steady-state values in times considerably less than $40 \mathrm{yr}$, the use of a $40-\mathrm{yr}$ duration should produce conservative results.

No attempt was made to calibrate the transport model to field measurements because of the following factors: the fracture geometry below the bulk wastes is unknown, the hydrogeologic processes at the boundary between the fractured limestone and alluvial aquifers are not understood, and a point measurement in a complex threedimensional flow field has an inherently large degree of uncertainty for contaminant plume characterization.

In order to investigate the effect of the source perturbation on the solute concentration, both its amplitude and duration were varied. The amplitude was varied over a $100 \%$ range in value from $\mathrm{C}_{0}$ to $2 \mathrm{C}_{0}$. It is unlikely that remedial action activities at the quarry will more than double the contaminant source strength (quarry waste waters are well mixed after $30 \mathrm{yr}$ of contaminant residence, steel canisters have probably rusted through, and few, if any, additional clean fraciures will be exposed to the contamination). A base-case value of $100 \%$ amplitude change was used in evaluating the effect of changes in other parameters. A base-case cleanup time of two years was assumed for $\Delta \mathrm{t}_{2}$ (Fig. 7). The sensitivity of the calculations to this parameter was investigated by allowing the cleanup time to range from one to ten years, even though the cleanup activities are expected to be completed in about two years.

The last parameter of interest for the study is the retardation factor, $R$. This factor, as shown in Eq. 2, is a function of the solute distribution coefficient, $K_{d}$. Since distribution coefficients vary significantly for different classes of dissolved materials and geologic conditions, assigning a single value becomes difficult. Conservative results can be obtained by assuming a $K_{d}$ value of zero $(R=1)$. This case corresponds to no sorption along the chosen flow path. The effects of a nonzero value for $R$ were investigated by performing calculations with an $R$ of 1, 5, 10, and 25. A base-case value of $R=1$ was used for the study to obtain conservative results and because no in-situ field measurements are available for this parameter. 


\section{RESULTS AND DISCUSSION}

Figure 8 shows the effect of separation distance on the downstream solute concentration as a function of time. In these plots, and all subsequent plots, the solid line represents the downstream concentrations for a constant-strength source at the quarry $(X=0)$ as calculated with Eq. 13 or 14 and the dashed line represents the concentrations calculated for the stepped source shown in Fig. 7 using Eg. 24 . All calculations begin at $t=0,40 \mathrm{yr}$ ago (1948). Forty years later (1988), the source is assumed to either (1) be perturbed and then reduced to zero after some time (response action scenario) or (2) remain at the same constant value (no-action alternative). Ordinate values in the plots are normalized to the initial contaminant concentration value, $C_{0}$.

In Fig. 8, all parameters are the same (V=300 ft/yr, $D=a V, b=100 \%$, $\Delta t_{1}=40 \mathrm{yr}, \Delta t_{2}=2 \mathrm{yr}$, and $R=1$ ) except for $X$, the separation distance, which is 1,000 , 2,500 , and $5,000 \mathrm{ft}$ in parts $a, b$, and $c$, respectively. In all cases, the constant-strength source approaches a steady-state value $\left(C / C_{0}=1\right)$ in less than 40 yr. As the separation distance increases, the solute breakthrough curve (BTC) broadens. That is, a longer time is required to achieve the same value of $C / C_{0}$. A broader BTC is caused by the combine $]$ effects of a larger separation distance and an increased dispersion coefficient. If the dispersion coefficient were zero, or some small constant value, slug flow would exist and the BTC would be a Heaviside function with a breakthrough time about equal to $\mathrm{X} / \mathrm{V}$.

For the stepped source, the time-dependent concentration profile behaves the same as the constant-strength source for the first $40 \mathrm{yr}$ of the calculation. At $40 \mathrm{yr}$, the perturbed source first increases the downstream concentrations above the constant-strength source values and then reduces the concentrations to zero due to the assumed cleanup activities. As is clear from Fig. 8, increasing the separation distance between the source and the point of interest decreases the effect of the perturbation on the downstream concentrations. A plot of the maximum difference between $\mathrm{C} / \mathrm{C}_{0}$ calculated with a stepped source and $\mathrm{C} / \mathrm{C}_{0}$ calculated with a constant-strength source is shown in Fig. 9 as a function of separation distance. Discontinuous breaks in the slope of the plot are the result of using four calculations to span the range of the independent variable (separation distance).

Figure 10 shows the effect of the average linear groundwater velocity on the downstream solute concentration for $X=2,500 \mathrm{ft}, D=a V, b=100 \%, \Delta t_{1}=40 \mathrm{yr}$, $\Delta t_{2}=2 \mathrm{yr}$, and $R=1$. Increasing the velocity (from 100 to $1,000 \mathrm{ft} / \mathrm{yr}$ ) leads to earlier solute breakthrough times and a stronger perturbed source influence. Figure 11 shows the effect of velocity on the maximum difference between $C / C_{0}$ calculated with $a$ constant-source strength and $C / C_{0}$ salculated with a perturbed source at a separation distance of $2,500 \mathrm{ft}$. As expected, increasing the velocity increases the maximum change.

Figure 12 illustrates the effect of dispersion on the downstream contaminant concentrations. In the calculations for Fig. 12, the dispersion coefficient was allowed to vary over three orders of magnitude from a low of $3 \times 10^{3} \mathrm{ft}^{2} / \mathrm{yr}$ to a high of $3 \times 10^{6} \mathrm{ft}^{2} / \mathrm{yr}$ for $\mathrm{X}=1,000 \mathrm{ft}, V=300 \mathrm{ft} / \mathrm{yr}, \mathrm{b}=100 \%, \Delta \mathrm{t}_{1}=40 \mathrm{yr}, \Delta \mathrm{t}_{2}=2 \mathrm{yr}$, and 
$\mathrm{R}=1$. As expected, increasing the dispersion coefficient broadens the BTC and produces a slightly less pronounced peak amplitude in $\mathrm{C} / \mathrm{C}_{0}$. Compsred to other parameter effects (such as distance, velocity, and retardation), dispersion is a secondary process.

Figure 13 shows the effect of the amplitude of the source perturbation on downstream concentrations for $X=2,500 \mathrm{ft}, V=300 \mathrm{ft} / \mathrm{yr}, \quad D=7.5 \times 10^{4} \mathrm{ft}^{2} / \mathrm{yr}$, $\Delta t_{1}=40 \mathrm{yr}, \Delta t_{2}=2 \mathrm{yr}$, and $R=1$. Increasing the amplitude of the perturbation (from 50 to 100\%) increases the effect on the dimensionless solute concentrations. The increase in the maximum change in $C / C_{0}$ relative to a constant-strength source at a separation distance of $2,500 \mathrm{ft}$ is nearly linear, as shown in Fig. 14. For small perturbations in source strength, the effect on downstream concentrations can be expected to be small.

Figure 15 shows the effect caused by the duration of the source perturbetion for $X=2,500 \mathrm{ft}, V=300 \mathrm{ft} / \mathrm{yr}, \quad D=7.5 \times 10^{4} \mathrm{ft}^{2} / \mathrm{yr}, \mathrm{b}=100 \%, \Delta \mathrm{t}_{1}=40 \mathrm{yr}$, and $R=1$. Increasing the duration of the perturbation from one to ten years significantly increases the downstream concentrations. For a realistic cleanup time of two years, $\mathrm{C} / \mathrm{C}_{0}$ increases by a maximum of about $16 \%$. Figure 16 shows the increase in $\mathrm{C} / \mathrm{C}_{0}$ relative to a constant-strength source at a separation distance of $2,500 \mathrm{ft}$. Discontinuous breaks in the slope of the response curves are the result of using four calculations to span the range of the independent variable (duration of the perturbation). An increase in the duration of the perturbation increases the maximum change between the two models.

Finally, Fig. 17 illustrates the effect of retardation on the downstream solute concentration for $X=1,000 \mathrm{ft}, V=300 \mathrm{ft} / \mathrm{yr}, D=3 \times 10^{4} \mathrm{ft}^{2} / \mathrm{yr}, \mathrm{b}=100 \%, \Delta \mathrm{t}_{1}=40 \mathrm{yr}$, and $\Delta t_{2}=2 \mathrm{yr}$. A separation distance of $1,000 \mathrm{ft}$ was used for the retardation sensitivity calculations to emphasize the effect. At larger separations, realistically estimated changes of $R$ do not produce observable changes in the solute concentrations. As the degree of retardation is increased, the effect of the perturbed source on the solute concentrations decreases and the time to achieve a steady-state solution or return to zero are both increased (see Fig. 18). These findings are in agreement with classical transport theory.

For the range of the parameters selected for the sensitivity analyses reported in this study, the following parameters have the greatest effect on the downstream solute concentrations: separation distance, retardation coefficient, and average linear velocity of the groundwater. Parameters of secondary significance are the amplitude of the perturbation and its duration. The least significant parameter is the system's dispersion coefficient. Since the separation distance from the quarry to the point of interest is precisely known, it will have no effect on the uncertainty of the predicted concentrations. While uncertainty in the retardation coefficient for the solute can have a very significant effect on uncertainties in the predicted downstream solute concentrations, the effects can be minimized by assuming the most conservative value for $K_{d}$, i.e., $K_{d}=0(R=1)$. When $R=1$, downstream concentration values are maximized and breakthrough times are minimized.

For a given separation distance and a conservative value for $K_{d}$, the greatest uncertainties in the concentration calculations are produced by uncertainties in the average groundwater velocity and the amplitude and duration of the source perturbation. For cleanup times less than about two years, a source perturbation 
amplitude of $50 \%$, and a groundwater velocity of $300 \mathrm{ft} / \mathrm{yr}$, the maximum change in $\mathrm{C} / \mathrm{C}_{0}$ between the stepped and constant sources is less than about $5 \%$ (Fig. 14) at the well field $(X=2,500 \mathrm{ft})$. This difference, as discussed above, is a conservative value for the model due to an assumed retardation coefficient of zero. Even small values of $k_{d}$ can further reduce the maximum change.

While the above sensitivity study is valid for the assumed model, field values may be different. Differences can arise from any of the simplifying assumptions made to develop an analytic solution to the advection-dispersion transport equation. These include effects due to a multidimensional, heterogeneous, and anisotropic flow system; use of an equivalent porous medium model; effects caused by the Femme Osage Slough and pumping at the municipal well field; and the shape of the time-dependent sou'ce at the quarry. Investigation of these effects will require use of a more complex numerical model and additional field work for model validation. 

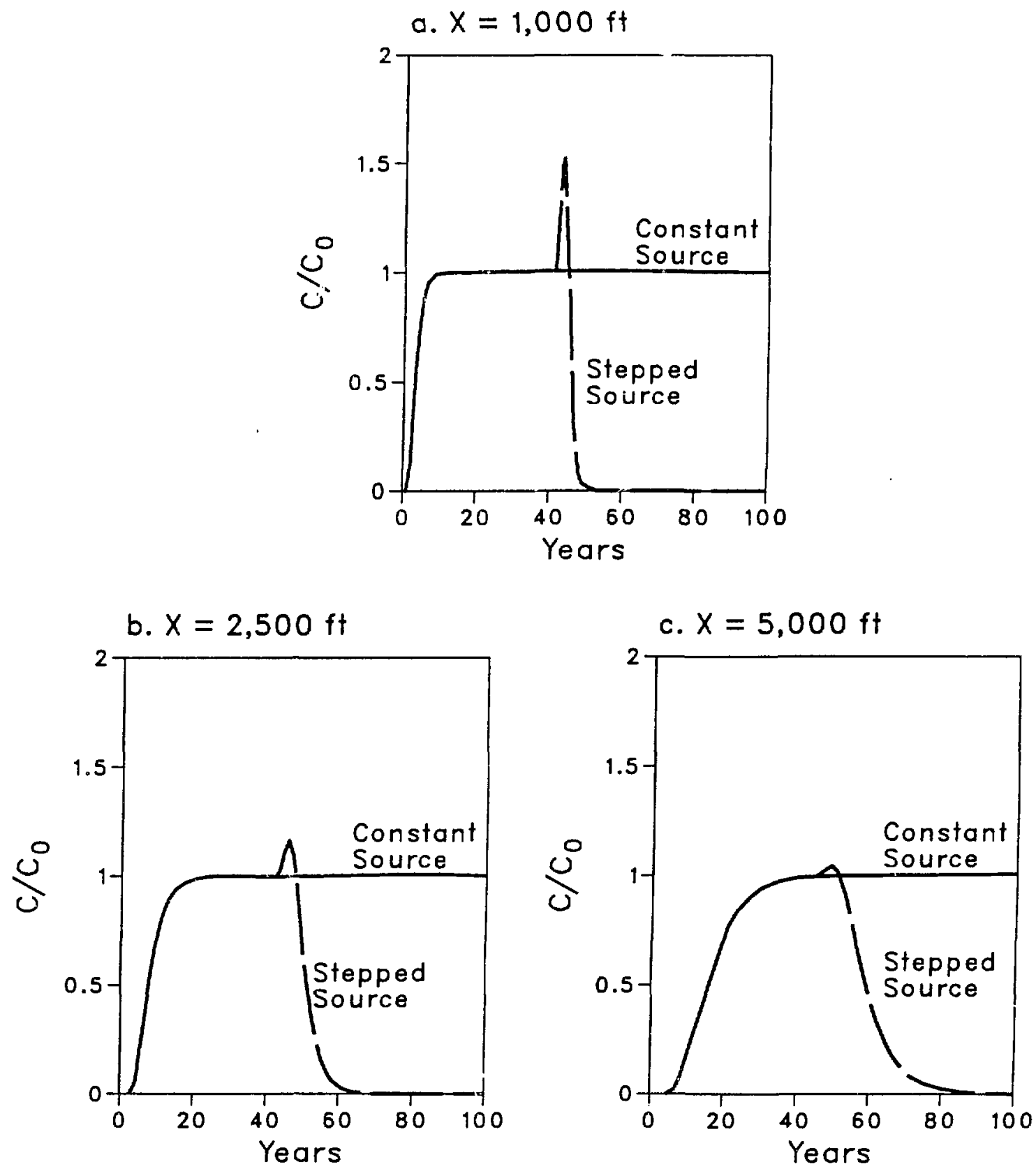

FIGURE 8 Solute Concentration as Function of Time for Various Separation Distances: (a) $1,000 \mathrm{ft}$, (b) $2,500 \mathrm{ft}$, and (c) $5,000 \mathrm{ft}\left(\mathrm{V}=300 \mathrm{ft} / \mathrm{yr}, D=3 \times 10^{4} \mathrm{ft}^{2} / \mathrm{yr}\right.$, $b=100 \%, \Delta t_{1}=40 \mathrm{yr}, \Delta t_{2}=2 \mathrm{yr} ;$ and $R=1$ ) 


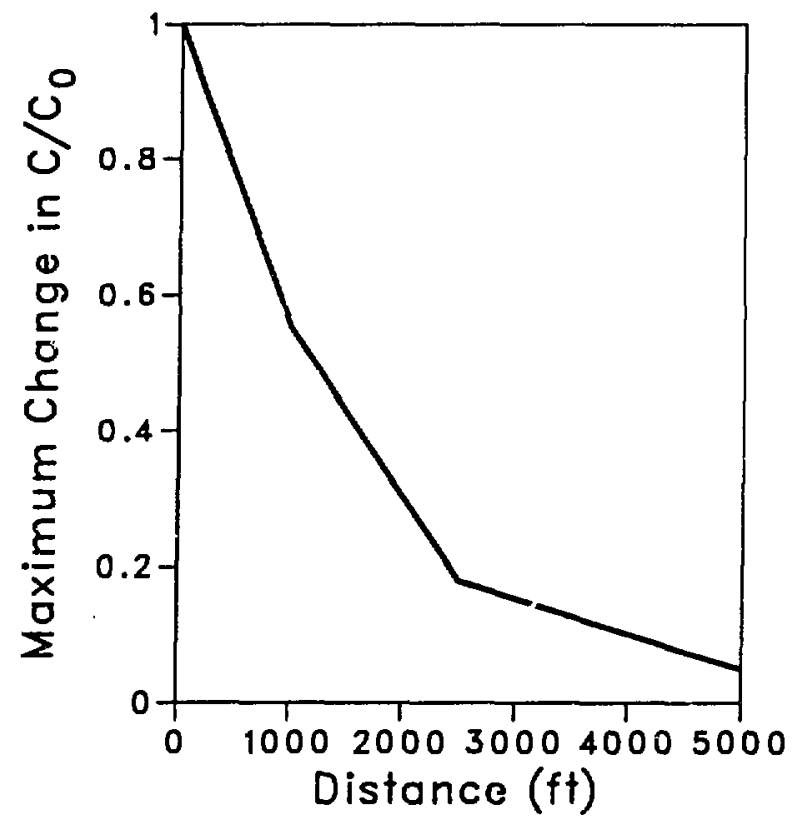

FIGURE 9 Maximum Change in $\mathrm{C} / \mathrm{C}_{0}$ as a Function of Distance from the Quarry 

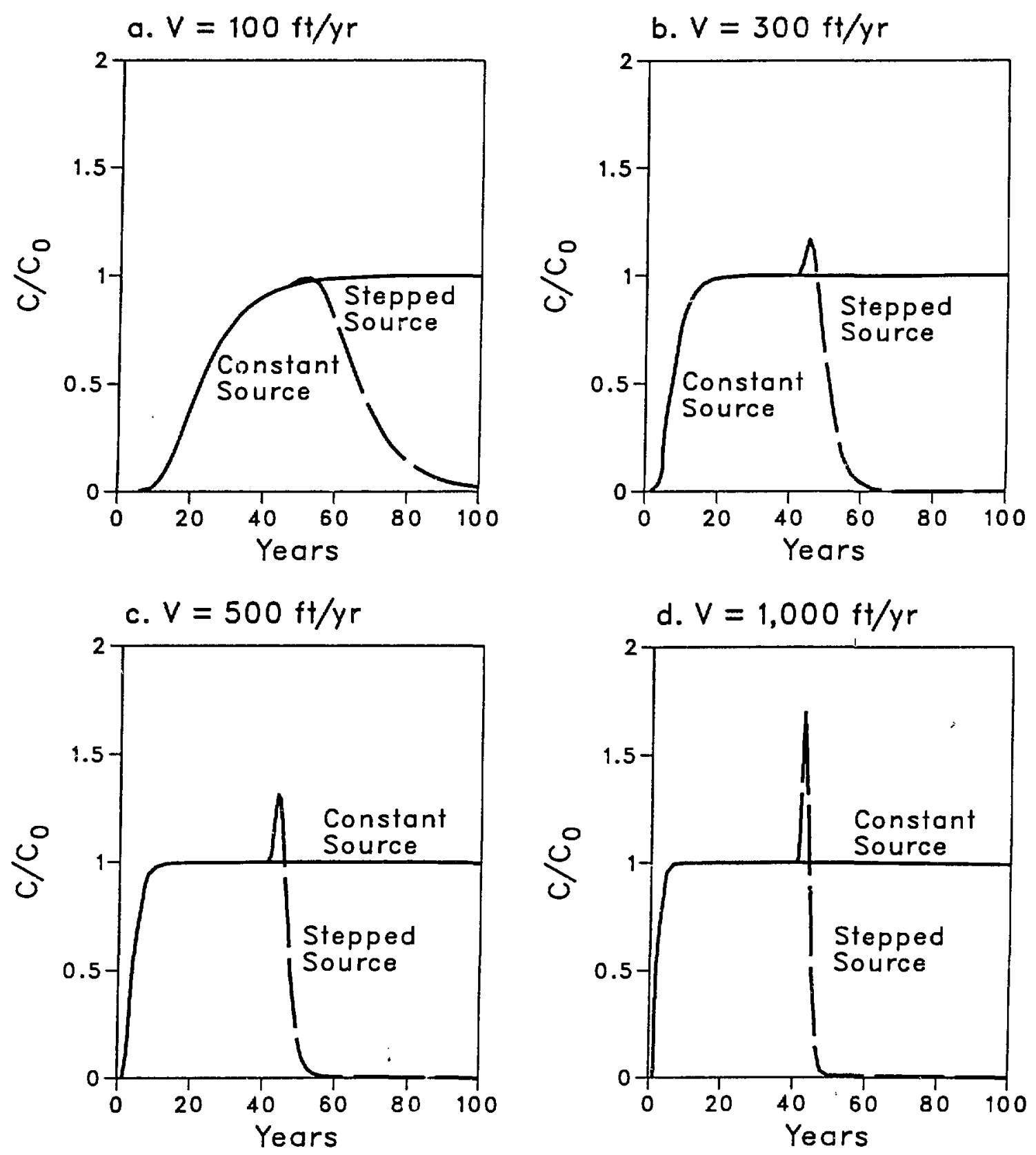

FIGURE 10 Solute Concentration as a Function of Time for Various Groundwater Velocities: (a) $100 \mathrm{ft} / \mathrm{yr}$, (b) $300 \mathrm{ft} / \mathrm{yr}$, (c) $500 \mathrm{ft} / \mathrm{yr}$, and (d) $1,000 \mathrm{ft} / \mathrm{yr}$ $\left(X=2,500 \mathrm{ft}, D=2.5 \times 10^{4} \mathrm{ft}^{2} / \mathrm{yr}, \mathrm{b}=100 \%, \Delta \mathrm{t}_{1}=40 \mathrm{gr}, \Delta \mathrm{t}_{2}=2 \mathrm{gr}\right.$, and $\left.\mathrm{R}=1\right)$ 




FIGURE 11 Maximum Change in $\mathrm{C} \mathrm{C}_{0}$ as a Function of the Average Linear Groundwater Velocity at $X=2,500 \mathrm{ft}$
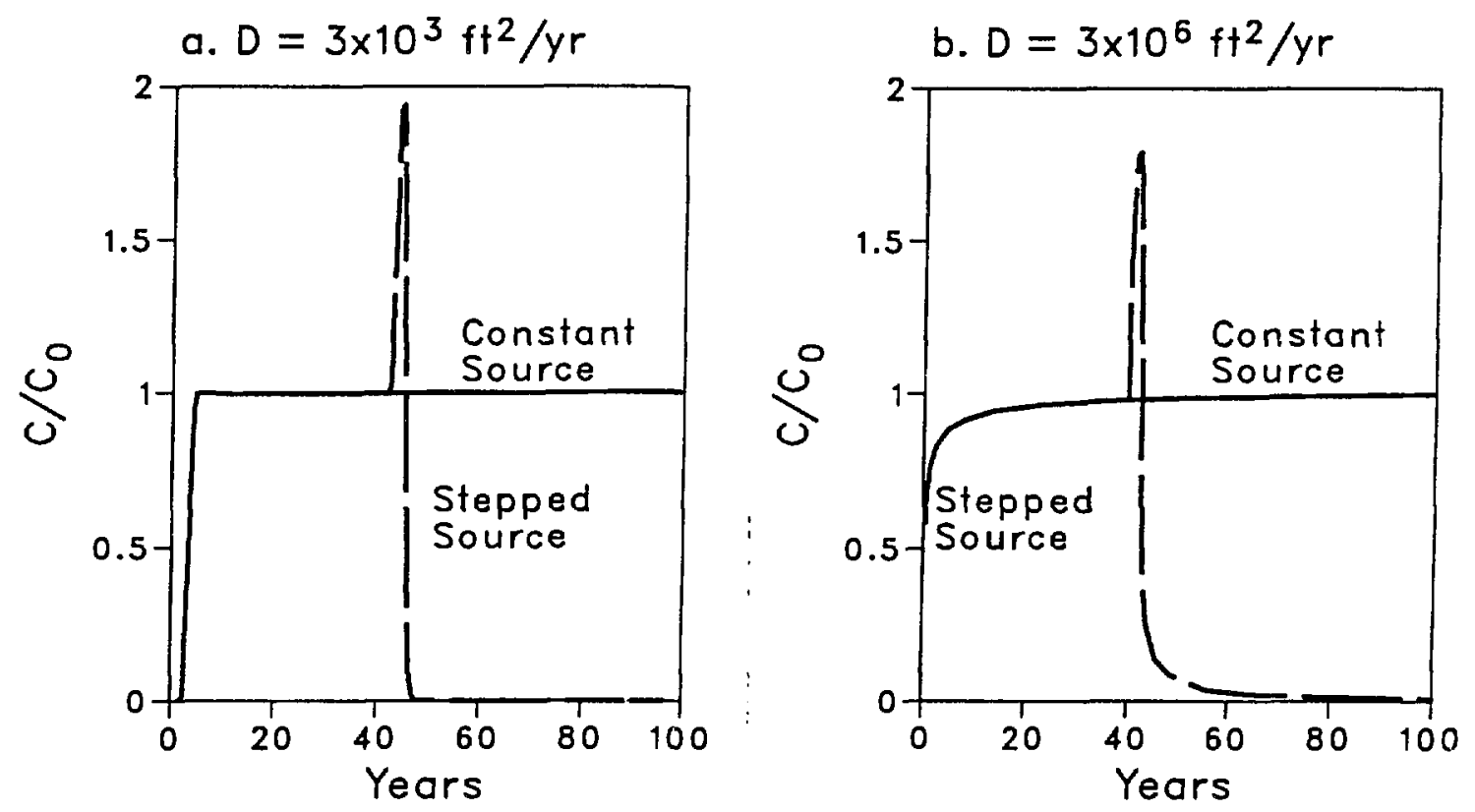

FIGURE 12 Solute Conçentration as a Function of Time for Different Dispersion Coefficients: (a) $3 \times 10^{3} \mathrm{ft}^{2} / \mathrm{yr}$ and (b) $3 \times 10^{6} \mathrm{ft}^{2} / \mathrm{yr}(\mathrm{X}=1,000 \mathrm{ft}$, $V=300 \mathrm{ft} / \mathrm{yr}, \mathrm{b}=100 \%, \Delta \mathrm{t}_{1}=40 \mathrm{gr}, \Delta \mathrm{t}_{2}=2 \mathrm{yr}$, and $\left.R=1\right)$ 
a. $b=25 \%$

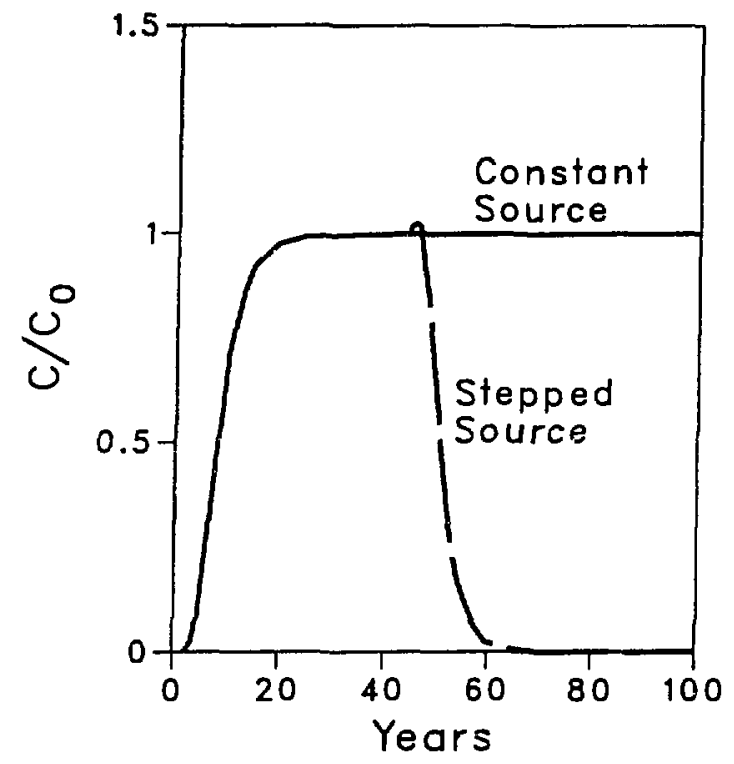

c. $b=75 \%$

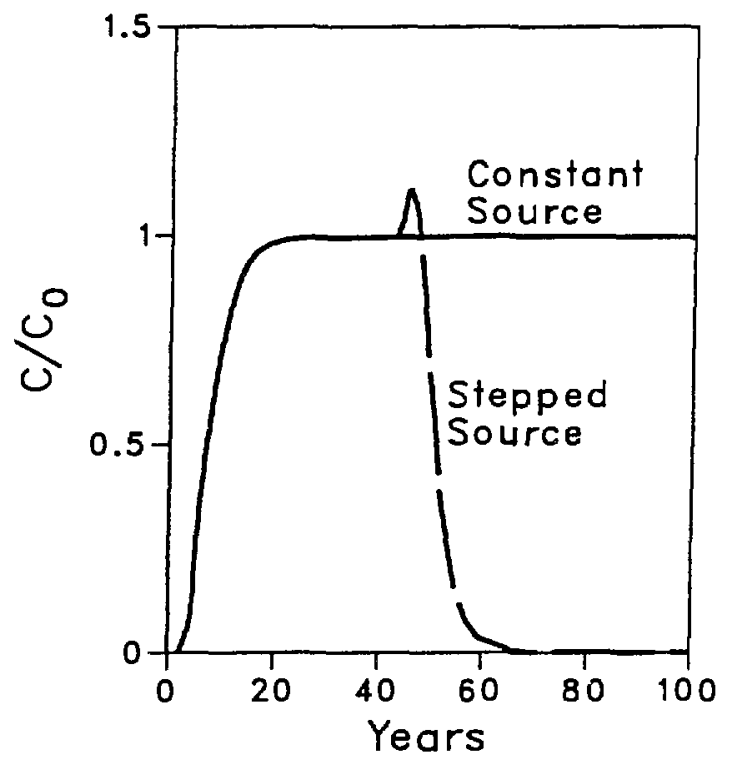

b. $b=50 \%$

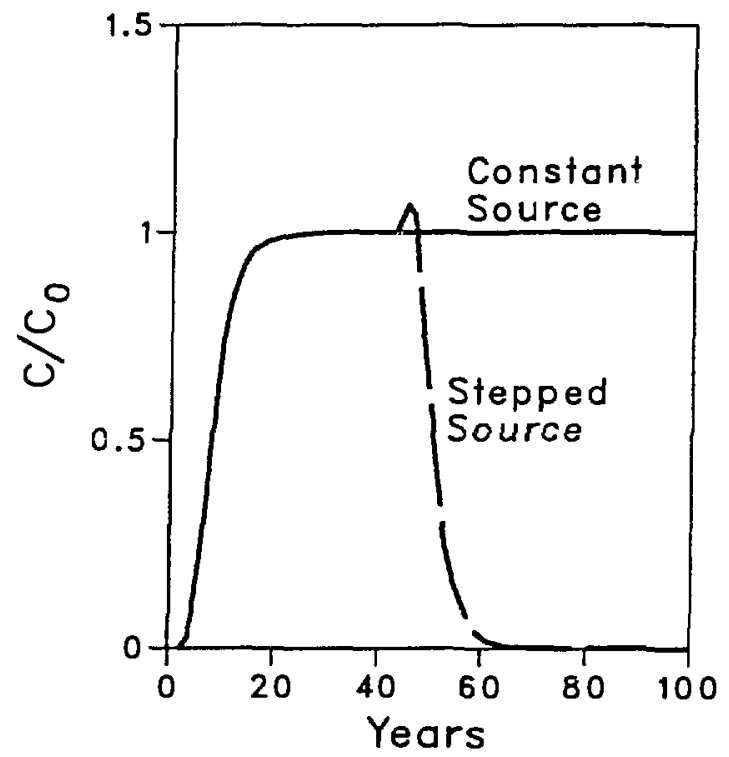

d. $b=100 \%$

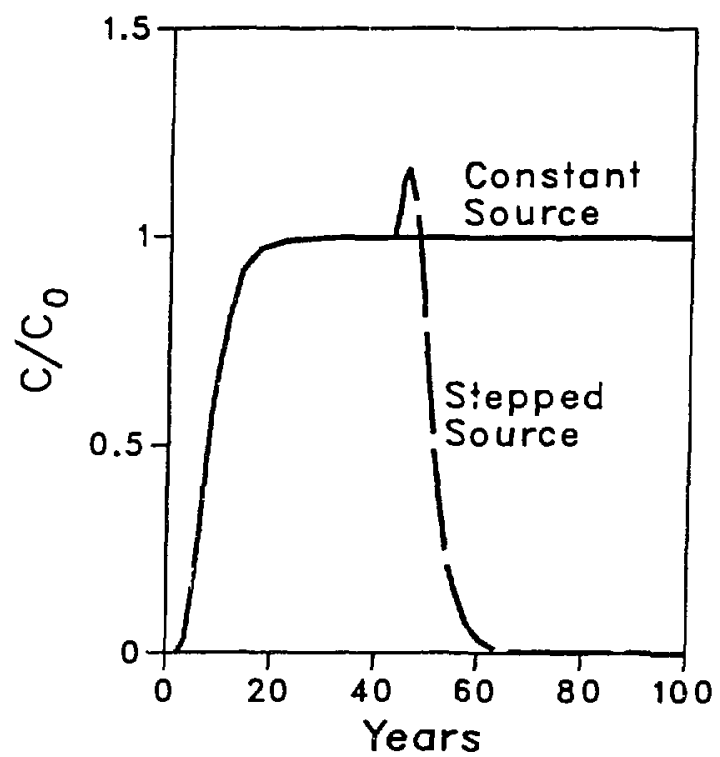

FIGUIRE 13 Solute Concentration as a Function of Time for Various Perturbation Amplitudes: (a) 25\%, (b) 50\%, (c) 75\%, and (d) $100 \%$ ( $X=2,500 \mathrm{ft}, \mathrm{V}=300 \mathrm{ft} / \mathrm{yr}$, $\mathrm{D}=7.5 \times 10^{4} \mathrm{ft}^{2} / \mathrm{yr}, \Delta \mathrm{t}_{1}=40 \mathrm{gr}, \Delta \mathrm{t}_{2}=2 \mathrm{yr}$, and $\mathrm{R}=1$ ) 


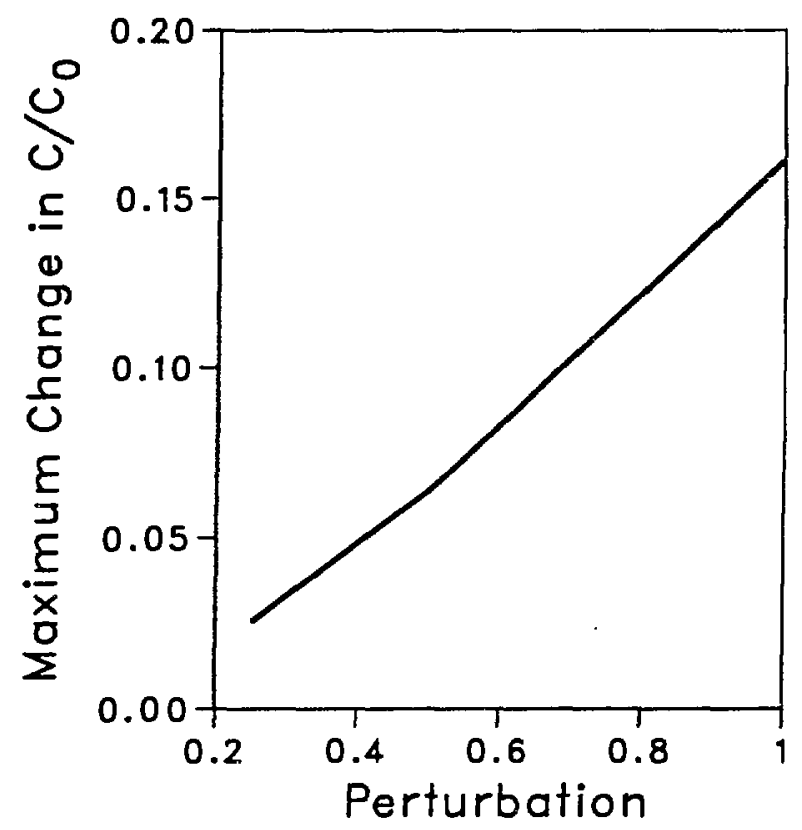

FIGURE 14 Maximum Change in $\mathrm{C} / \mathrm{C}_{0}$ as a Funetion of the Amplitude of the Source Perturbation at $X=2,500 \mathrm{ft}$ 
a. $\Delta t_{2}=1 \mathrm{yr}$

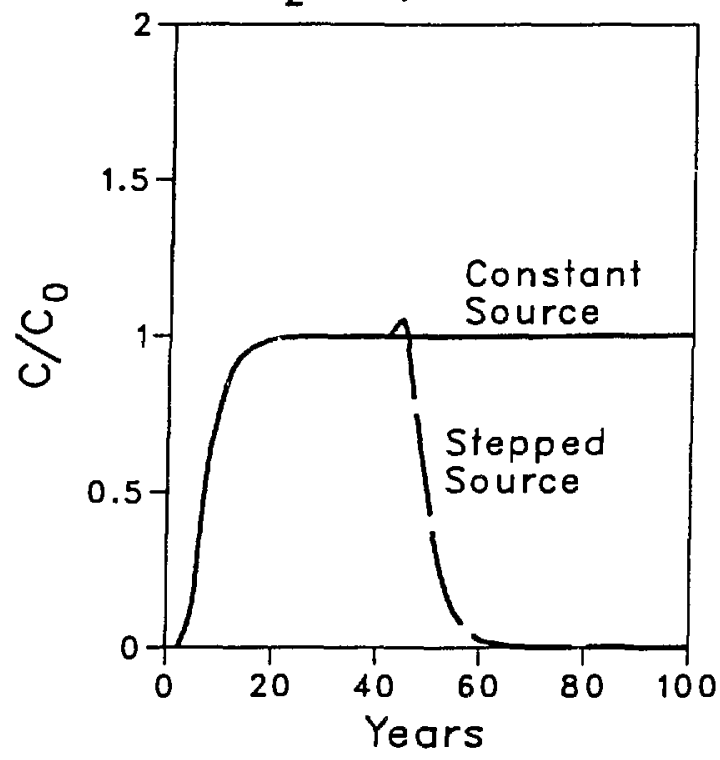

c. $\Delta t_{2}=5 \mathrm{yr}$

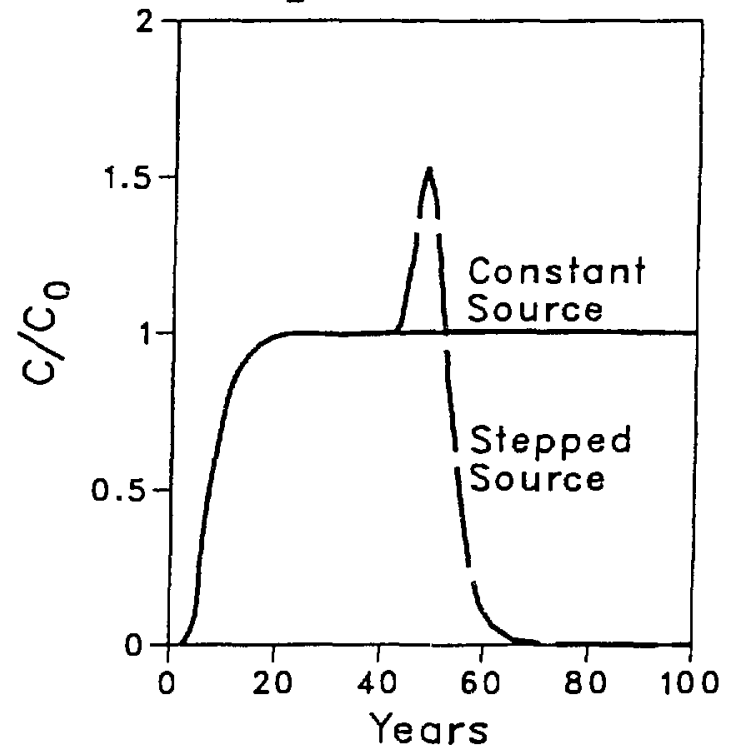

b. $\Delta t_{2}=2 y r$

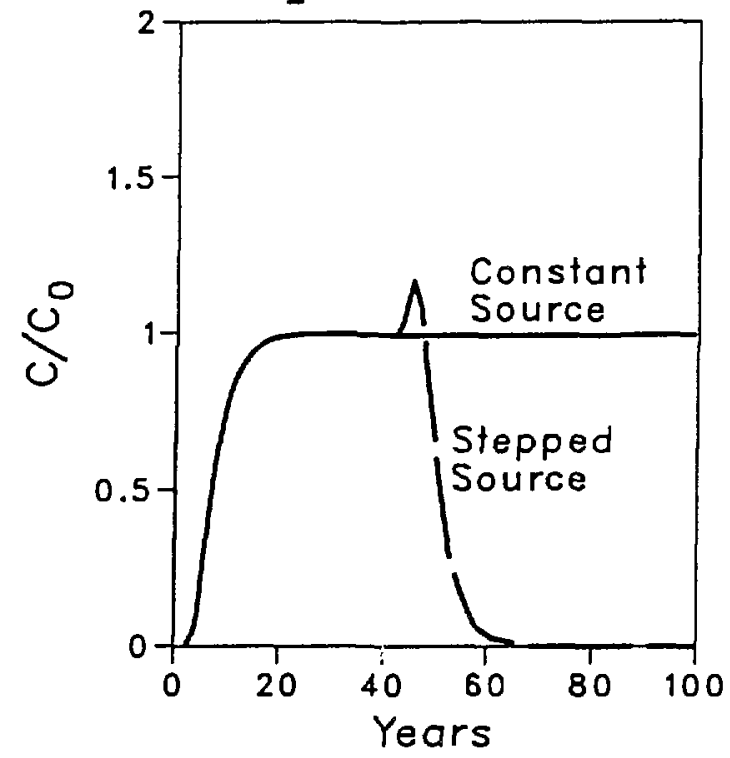

d. $\Delta t_{2}=10 y r$

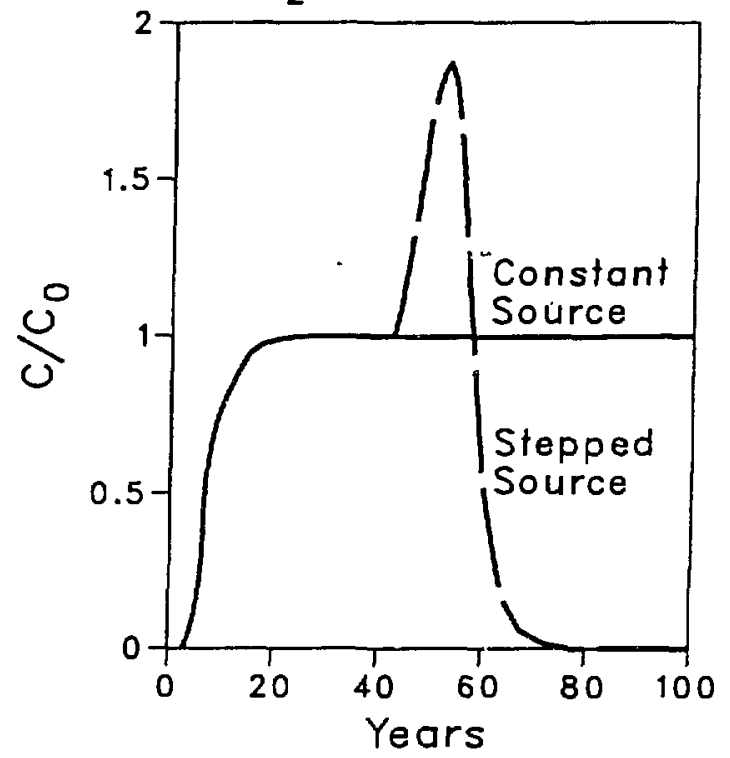

FIGURE 15 Solute Concentration as a Function of Time for Various Cleanup Durations: (a) $1 \mathrm{yr}$, (b) $2 \mathrm{yr}$, (c) $5 \mathrm{yr}$, and (d) $10 \mathrm{yr}$ (X $=2,500 \mathrm{ft}, \mathrm{V}=300 \mathrm{ft} / \mathrm{yr}, \mathrm{D}=7.5 \times 10^{4} \mathrm{ft}^{2} / \mathrm{yr}$, $b=100 \%, \Delta t_{1}=40 \mathrm{yr}$, and $\mathrm{R}=1$ ) 
27

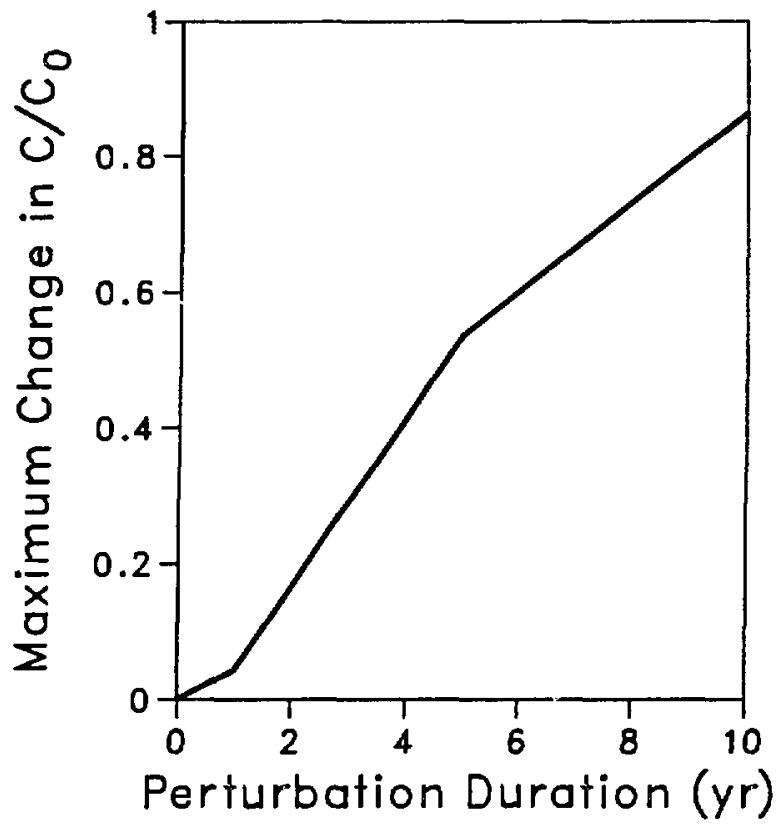

FIGURE 16 Maximum Change in $\mathrm{C} \mathrm{C}_{0}$ as a Function of the Duration of the Source Perturbation at $X=2,500 \mathrm{ft}$ 
a. $R=1$

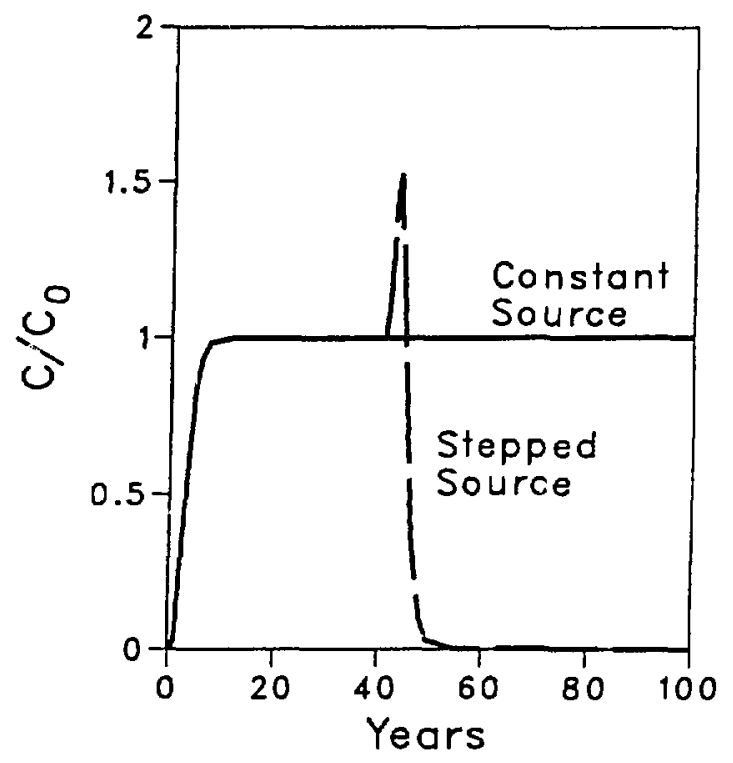

c. $R=10$

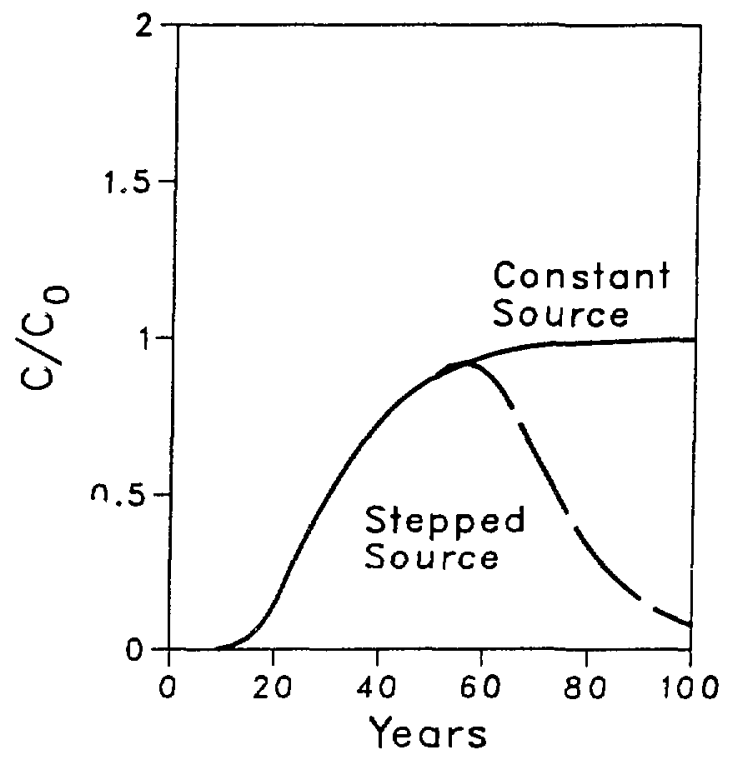

b. $R=5$

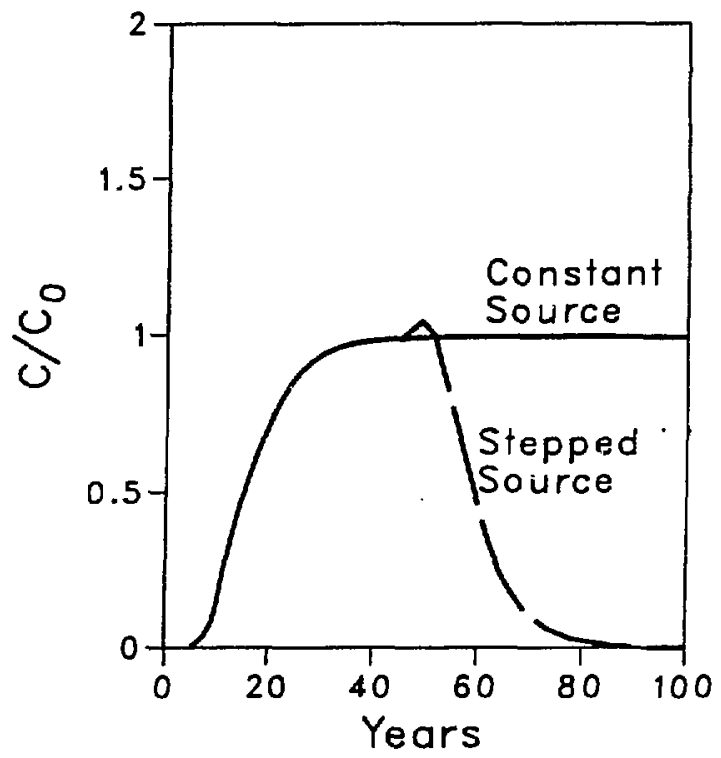

d. $R=25$

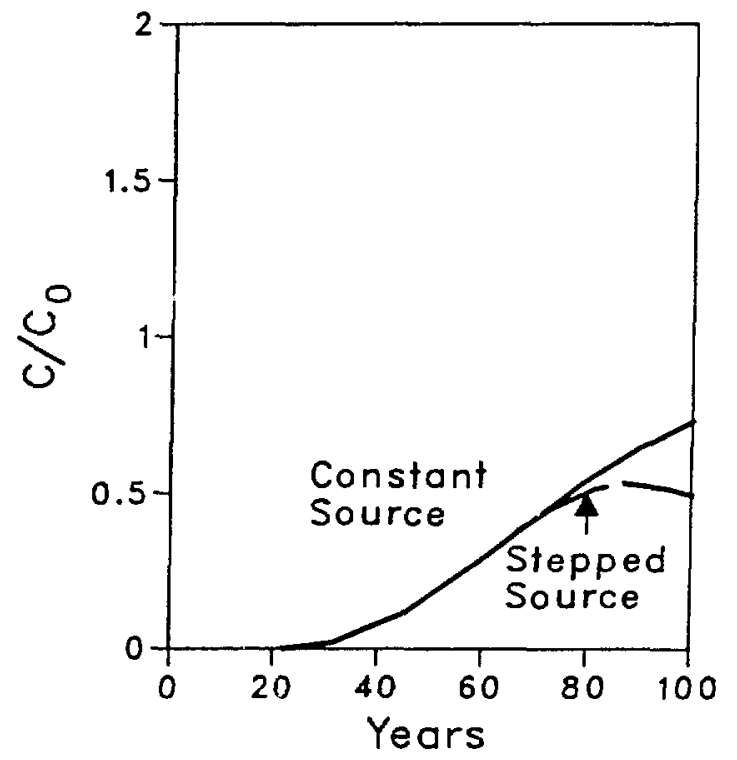

FIGURE 17 Solute Concentration as a Function of Time for Various Retardation Factors: (a) $1_{2}$ (b) 5 , (c) 10 , and (d) $R=25$ ( $X=1,000 \mathrm{ft}, V=300 \mathrm{ft} / \mathrm{yr}$, $\mathrm{D}=3 \times 10^{4} \mathrm{ft}^{2} / \mathrm{yr}, \mathrm{b}=100 \%, \Delta \mathrm{t}_{1}=40 \mathrm{gr}$, and $\Delta \mathrm{t}_{2}=2 \mathrm{yr}$ ) 


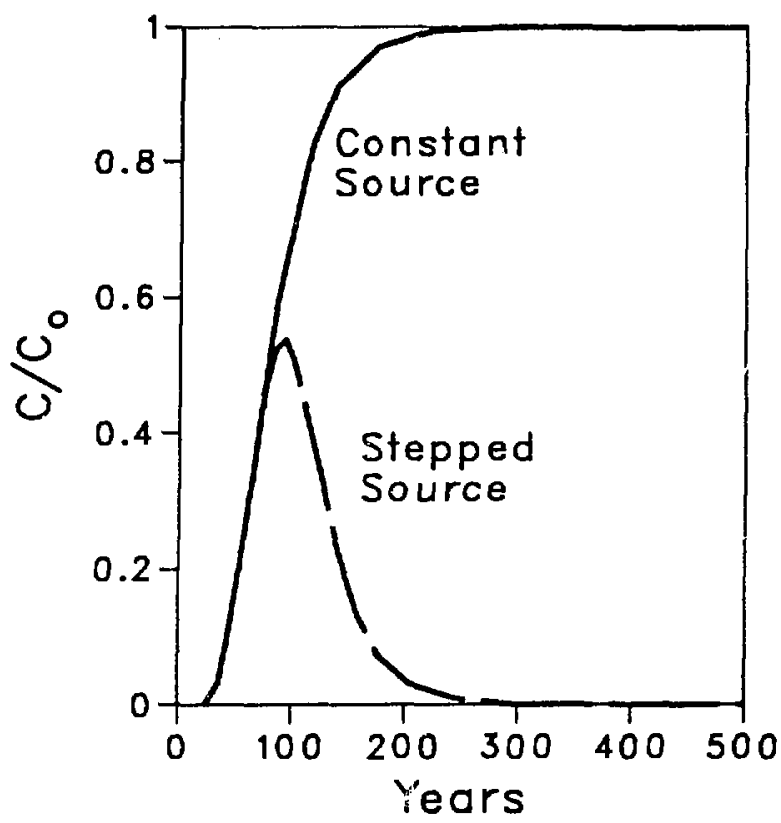

FIGURE 18 Solute Concentration as a Function of Time for 500 yr at Maximum Retardation $(R=25)$ 


\section{REFERENCES}

Abramowitz, M., and I.A. Stegun, 1972, Handbook of Mathematical Functions with Formulas, Graphs, and Mathematical Tables, John Wiley and Sons, New York.

Bear, J., 1972, Dynamics of Fluids in Porous Media, American Elsevier Publishing Co., New York.

Berkeley Geosciences Associates, 1984, Characterization and Assessment for the Weldon Spring Quarry Low-Level Radioactive Waste Storage Site, prepared for Oak Ridge National Laboratory, Berkeley Geosciences Associates, Berkeley, Calif.

Ditkin, V.A., and A.P. Prudnikov, 1967, Formulaire Pour Le Calcul Operationnel, Masson et Cie, Editeurs, Paris, France.

Freeze, R.A., and J.A. Cherry, 1979, Groundwater, Prentice-Hall, Inc., Englewood Cliffs, N.J.

Grisak, G.E., and J.F. Pickens, 1980, Solute Transport Through Fractured Media, 1, The Effect of Matrix Diffusion, Water Resources Research, 16(4):5632-5672.

Hildebrand, F.B., 1976, Advanced Calculus for Applications, Prentice-Hall, Inc., Englewood Cliffs, N.J.

Lallemand-Barres, A., and P. Peaudecerf, 1978, Recherche des Relations Entre la Valeur de la Dispersivite Macroscopique d'un Milieu Aquifere, Ses Autres Caracteristiques et les Conditions de-Mesure, Bulletin Bureau Geologique Minieres, Sect. 3, Vol. 4, pp. 277-284.

MacDonell, M.M., J.M. Peterson, and I.E. Joya, 1989, Engineering Evaluation/Cost Analysis for the Proposed Management of Contaminated Water in the Weldon Spring Quarry, U.S. Department of Energy Report DOE/OR/21548-039, Jan.

Morrison-Knudson Engineering, Inc., 1988, Remedial Investigation for Quarry Bulk Wastes, Report 5121R-303-00, Morrison-Knudson Engineers, Inc., San Francisco.

Ogata, A., and R.B. Banks, 1961, A Solution of the Differential Equation of Longitudinal Dispersion in Porous Media, U.S. Geological Survey Professional Paper 411-A, U.S. Government Printing Office, Washington, D.C.

Streltsova-Adams, T.D., 1978, Well Hydraulics in Heterogeneous Aquifer Formations, Advances in Hydroscience, V.T. Chow, ed., 11:357-423.

Tomasko, D., et al., 1987, Parameter Sensitivity and Importance for Radionuclide Transport in Double-Porosity Systems, Proc. DOE/AECL 1987 Conf. on Geostatistical, Sensitivity, and Uncertainty Methods for Ground-Water Flow and Radionuclide Transport Modeling, Battelle Press, Columbus, Ohio, pp. 297-321. 